\title{
What Attorneys and Factfinders Need to Know About Mild Traumatic Brain Injuries
}

\author{
Noah K. Kaufman ${ }^{1,2}$ (D) Shane S. Bush ${ }^{3,4} \cdot$ Mario R. Aguilar $^{5}$ \\ Received: 11 January 2019 / Accepted: 16 May 2019 / Published online: 1 June 2019 \\ (C) Springer Science+Business Media, LLC, part of Springer Nature 2019
}

\section{Introduction}

Historically, two divergent positions on the long-term impact of mild traumatic brain injury (mTBI), also commonly termed concussion (Ruff, Iverson, Barth, Bush, \& Broshek, 2009), existed in the scientific literature. One stance was that a relatively small percentage of mTBI patients experience lasting problems for physiogenic (i.e., medically verifiable, neurological, or physical) reasons. The second view was that residual problems arising from mTBI are more psychogenic (i.e., medically unverifiable, non-neurological, or psychological). Uzzell (1999) and Ruff, Camenzuli, and Mueller (1996), for example, were in the former camp, whereas others, including Binder (1997) and Larrabee (1999), leaned away from a neurological causation explanation for residual problems, pending more rigorous scientific investigation. In his cleverly titled presentation from this time period, "Brain Damage Caused by Collision with Forensic Neuropsychologists," Bauer (1997) urged neuropsychologists practicing in the legal arena to think very carefully before opining on a causeeffect relationship between mTBI and later impairment:

Noah K. Kaufman

noahk@zianet.com

1 Center for Neuropsychological Studies, 1188 West Hadley, Las Cruces, NM 88005, USA

2 Department of Psychiatry, Paul L. Foster School of Medicine, Texas Tech University Health Sciences Center, 4615 Alameda, El Paso, TX 79905, USA

3 Long Island Neuropsychology, P.C, 290 Hawkins Avenue, Suite B, Lake Ronkonkoma, NY 11779, USA

4 Department of Psychology, College of Arts \& Sciences, University of Alabama, Tuscaloosa, AL 35487-0348, USA

5 Neurology Private Practice, 1240 S. Telshor Blvd. Ste. C, Las Cruces, NM 88011, USA
First, patients who are falsely labeled as "impaired" are sometimes done a potentially serious disservice by their treating neuropsychologists because such labels often engender self-fulfilling prophecies. Patients may be led to believe that they are incapable of getting better; that they are permanently disabled, and that they lack control over their present and future status. Further, by virtue of being inappropriately diagnosed, patients may be referred for expensive and labor-intensive treatment or management services that they either don't need or which is downright detrimental to their post-accident recovery. Second, if these errors exist with any prevalence in litigation settings, then appropriate and reasoned professional activity within the neuropsychological community is undermined. We are ill-served if we do not confront and discuss this problem directly. (p. 1)

Researchers have had many years to study mTBI, resulting in findings that bring the issues into clearer focus, although not entirely. The purpose of this article is to give attorneys and factfinders an updated, scientifically informed perspective on mTBI, with an emphasis on the following: (1) the different levels of brain injury severity; (2) the shortcomings of the postconcussional syndrome diagnosis (e.g., reliance on the outdated "organicity" concept and failure to address intentional symptom production); (3) illusory correlation (i.e., when no true relationship exists between variables); (4) alternative causes of symptoms underlying a postconcussional syndrome diagnosis; (5) base rates (i.e., the diagnostic importance of knowing how common a condition is in a given population); (6) uncertainty about the base rate of postconcussional syndrome; (7) iatrogenesis (i.e., when healthcare professionals' actions unintentionally harm patients); (8) alternative diagnostic options (other than postconcussional syndrome); (9) ethical considerations; and, finally, (10) legal considerations (e.g., problems with reasonable medical certainty and potential limitations on admissibility of postconcussional syndrome evidence). 
Table 1 Four categories of traumatic brain injuries

\begin{tabular}{lllll}
\hline & mTBI & $\begin{array}{l}\text { Complicated-mild } \\
\text { TBI }\end{array}$ & $\begin{array}{l}\text { Moderate } \\
\text { TBI }\end{array}$ & $\begin{array}{l}\text { Severe } \\
\text { TBI }\end{array}$ \\
\hline LOC & $\leq 30 \mathrm{~min}$ & $\begin{array}{c}\text { Same as mTBI plus } \\
\text { intracranial } \\
\text { bleeding } \\
\text { PTA }\end{array}$ & $\begin{array}{c}30 \mathrm{~min} \text { to } \\
24 \mathrm{~h}\end{array}$ & $>24 \mathrm{~h}$ \\
$\begin{array}{c}\text { GCS } \\
\text { score as mTBI plus } \\
\text { intracranial } \\
\text { bleeding }\end{array}$ & 1 to 7 days & $>7$ days \\
postinjury & $\begin{array}{c}\text { Same as mTBI plus } \\
\text { intracranial } \\
\text { bleeding }\end{array}$ & 9 to 12 & 3 to 8 \\
\hline
\end{tabular}

LOC loss of consciousness, PTA posttraumatic amnesia, GCS Glasgow Coma Scale

\section{Characterizing Brain Injury Severity}

In the scientific literature, traumatic brain injuries (TBIs) are now divided into four levels of severity: (1) mild, (2) complicated-mild, (3) moderate, and (4) severe. Broadly speaking, mTBIs are defined by any alteration in mental state (e.g., feeling "dazed"), loss of consciousness (LOC) of $30 \mathrm{~min}$ or less, postinjury forgetfulness (called posttraumatic amnesia [PTA]) of $24 \mathrm{~h}$ or less, and a Glasgow Coma Scale (GCS) score (an index of brain responsiveness) of 13 or higher, beginning at $30 \mathrm{~min}$ after the injury. Complicated mild TBIs are mTBIs plus intracranial (i.e., inside the skull) bleeding, typically detected with an emergency room brain scan (e.g., CT or MRI). Moderate and severe TBIs require progressively more severe injury characteristics. Although not diagnostically necessary, the more severe injuries may also have intracranial bleeding. Table 1 summarizes these four categories of traumatic brain injuries.

Of the available mTBI definitions (see Boxes 1-5), perhaps the most widely used comes from the American Congress of Rehabilitative Medicine (ACRM; AndersonBarnes, Weeks, \& Tsao, 2010), making it particularly helpful in forensic cases. However, no mention is made in this definition about intracranial bleeding, which is the hallmark of a complicated-mild TBI. It is therefore important to emphasize that any definition of mTBI should exclude bleeding inside the skull, thereby differentiating between mTBIs and complicated-mild TBIs. If an mTBI definition is used that does allow for intracranial bleeding (see the World Health Organization [WHO] mTBI definition in Box 2), avoidable confusion about legal cause and harm/damage may work its way into the case, because complicated-mild TBIs can sometimes cause harm/damage.
Box 1 Based on Stein definitions of mTBI (Stein, 1996)

Definition \#1:

- LOC $<20 \mathrm{~min} ; \&$

- $\mathrm{GCS}>13 ; \&$

- PTA $<24 \mathrm{~h}$.

Definition \#2:

- Altered mental status; or

- LOC $<5$ min; or

- $\mathrm{GCS}=14$; or

- GCS $=15+$ mild amnesia; \&

- No TBI-related focal neurologic deficits (e.g., asymmetrical mydriasis [one pupil larger than other], ptosis [droopy eyelid], anosmia [loss of smell], dysphagia [difficulty swallowing], diplopia [double vision], paresis [weakness], vertigo [spinning feeling], dysconjugate gaze [irregular visual tracking], nystagmus [involuntary eyeball movement], palsy [paralysis], dysarthria [poor speech articulation], dyspraxia [unskilled motor coordination], appendicular ataxia [poor motor timing/smoothness], paresthesia [prickling/burning sensation], hypotonia [loss of muscle tone], hyperkinesis [tic, tremor]).

Box 2 Based on World Health Organization (WHO) definition of mTBI (Carroll, Cassidy, Holm, Kraus, \& Coronado, 2004; Holm, David Cassidy, Carroll, \& Borg, 2005)

- Confusion or disorientation; \&/or

- $\mathrm{LOC} \leq 30 \mathrm{~min} ; \& /$ or

- PTA $<24 \mathrm{~h} ; \& /$ or

- Focal signs; \&/or

- Brief postinjury seizures; \&/or

- Intracranial lesion not needing surgical intervention; \&

- GCS $\geq 13$ at 30 min from injury; \&

- Symptoms not caused by any of these: drugs or alcohol, prescribed medication, other injuries or treatment (e.g., broken jaw or intubation), psychological reactions to the injury, language background, other medical problems, or open head injury.

Box 3 Based on Center for Disease Control \& Prevention (CDC) recommended conceptual definition of $\mathrm{mTBI}$ (Gerbeding \& Binder, 2003)

- Observed, or self-reported, "Transient confusion, disorientation, or impaired consciousness" of any length; \&/or

- Observed, or self-reported, "Dysfunction of memory around the time of injury" of any length; \&/or

- Observed seizure(s) immediately after injury; \&/or

- Observed "irritability, lethargy, or vomiting... among infants and very young children" after injury; \&/or

- Observed "headache, dizziness, irritability, fatigue or poor concentration...or altered consciousness...soon after injury....among older children and adults"; \&

- No observed, or self-reported, LOC of $>30 \mathrm{~min} ; \&$

- No PTA $>24 \mathrm{~h} ; \&$

- Not a "Penetrating craniocerebral injury." 
Box 4 Based on American Congress of Rehabilitation Medicine (ACRM) definition of mTBI (Kay et al., 1993)

- Any LOC; \&/or

- Any retrograde or anterograde amnesia surrounding the injury; \&/or

- "[A]ny alteration in mental state at the time of the accident (e.g., feeling dazed, disoriented, or confused); \&/or

- "[F]ocal neurological deficit(s) [see Box 1] that may or may not be transient"; \&

- GCS $\geq 13$ by 30 min postinjury; \&

- No LŌC > $30 \mathrm{~min} ; \&$

- No PTA > $24 \mathrm{~h}$.

Box 5 Based on American Academy of Pediatrics definition of minor closed head injury (Bergman et al., 1999)

- Observed LOC $<1$ min; \&/or

- "seizure immediately after injury"; \&/or

- "vomited after injury"; \&/or

- "headache and lethargy"; \&

- No head "CT reveal[ing] lesion"; \&

- No "signs and/or symptoms of intracranial problems" (e.g., focal neurologic deficits [see Box 1]); \&

- No "multiple trauma" (cervical spine injury, fractured jaw, etc.); \&

- No "unobserved" LOC; \&

- No "language barrier" (in child or reporting parent[s]); \&

- No pre-existing neurological disorder aggravated by injury (e.g., "arteriovenous malformations or shunts"); \&

- No drugs or alcohol involved.

With respect to recovery and outcome, it is now commonly accepted that complicated-mild TBIs are as serious as moderate TBIs (Fay et al., 2010; Kashluba, Hanks, Casey, \& Millis, 2008; Levin et al., 2008; Williams, Levin, \& Eisenberg, 1990), making the distinction between a regular mTBI and a complicated-mild TBI very important. Regrettably, whereas the line between a moderate and a severe TBI has long been brighter and easier to draw, the definition of "mild" TBI has historically been less clear, often including complicated-mild TBIs in the definition. This diagnostic gray area presents challenges for clinicians who have not stayed up to speed with the mTBI research, especially the literature generated since Bauer's late 90s presentation (e.g., Carroll et al., 2014; Cassidy, Boyle, \& Carroll, 2014; Dikmen, Machamer, \& Temkin, 2017; Godbolt et al., 2014; Hung et al., 2014; Jacobs et al., 2010; Kristman et al., 2014; Kulbe \& Geddes, 2016; Lagarde et al., 2014; Levin \& Diaz-Arrastia, 2015; Panenka et al., 2015; Papa et al., 2013; Ponsford, Cameron, Fitzgerald, Grant, \& Mikocka-Walus, 2011; Salmi et al., 2014; Shin, Bales, Dixon, \& Hwang, 2017; Silverberg et al., 2015; van der
Naalt et al., 2017; Wäljas et al., 2015; Yuh et al., 2014; and Zetterberg, Smith, \& Blennow, 2013).

Future brain scanning research may eventually establish reliable links between severity levels of intracranial bleeding (e.g., bleeds that do, versus do not, invade parenchyma [the functional tissue of the brain]) and certain long-term outcomes, thereby putting complicated-mild TBIs, and the associated long-term effects, on a finer scale of measurement. At present, however, brain injury severity is not characterized this way; that is, all intracranial bleeding associated with $m T B I$ is viewed equally. Similarly, because researchers presently differentiate between mTBIs and complicated-mTBIs, it is necessary for clinicians to also make this relatively subtle, but crucial, distinction in their cases, including their medico-legal/forensic cases. To this point, our discussion of mTBIs and postconcussional syndrome does not extend to complicated-mild TBIs (i.e., concussions that also include intracranial bleeding), which we acknowledge as more serious than mTBIs (i.e., concussions that do not include intracranial bleeding).

\section{Shortcomings of the Postconcussional Syndrome Diagnosis}

According to the International Classification of Diseases, Tenth Revision, Clinical Modification (ICD-10-CM; Goodheart, 2014; WHO, 2018), there is a billable diagnosis called "postconcussional syndrome" with a diagnostic code of F07.81. It comes under consideration for those who have experienced an mTBI, followed subsequently by lingering symptoms that extend well beyond the immediate/acute time period after the injury. For a healthcare professional to make this diagnosis, the following diagnostic criteria must be met:

The organic and psychogenic disturbances observed after closed head injuries. Post-concussion syndrome includes subjective physical complaints (i.e. headache, dizziness), cognitive, emotional, and behavioral changes. These disturbances can be chronic, permanent, or late emerging.

There are many problems with this diagnosis. To begin with, the definition of "organic" is unclear. According to the INS Dictionary of Neuropsychology (Loring \& Meador, 1999), organic brain syndrome is an "Obsolete nonspecific term referring to syndromes arising from brain disease" (p. 119). In other words, this resource indicates that the organicity construct is no longer considered helpful because it is too general. Another older neuropsychology tome published in 2004 
(Lezak, Howieson, \& Loring, 2004) stated that organicity is hard, or impossible, to measure:

Despite many ingenious efforts to devise a test or examination technique that would be sensitive to organicity per se - a neuropsychological litmus paper, so to speak - no one behavioral phenomenon could be found that was shared by all brain injured persons but by no one else. (p. 17)

From these two older authorities, Loring and Meador (1999) and Lezak et al. (2004), it is evident that the organicity concept has been outdated for many years.

Neuropsychologists can measure deficits in cognitive functioning extremely well. But establishing that the cognitive deficits had their causative roots in brain disease (i.e., organicity) can be challenging, unless, for example, there is unequivocal evidence of brain damage, as found in the brain scans of those who have suffered strokes, penetrating injuries, complicated-mild traumatic brain injuries, moderate and severe closed-head injuries with intracranial bleeding, brain infections, meningeal infections (e.g., subdural empyema), and so forth. Because postconcussional syndrome is attributed to concussions, as opposed to more severe brain damage like bleeding or infection inside the skull, current brain scanning techniques are not sensitive to so-called organicity. For example, determining whether an abnormal brain scan is causally related to a concussion and/or cognitive deficits is frustrated by the fact that many people without concussions and/or cognitive deficits have abnormal brain scans (Evans, 2017; Katzman, Dagher, \& Patronas, 1999; Kim, Illes, Kaplan, Reiss, \& Atlas, 2002; Morris et al., 2009; Vernooij et al., 2007). As noted by Morris et al. (2009), one out of every 37 "neurologically asymptomatic" persons receiving a brain MRI will have abnormal results. Meanwhile, many people with normal brain scans have significant cognitive deficits measured by neuropsychological tests (Decobert et al., 2005), indicating that brain scans fail to detect cognitive deficits identified by neuropsychological testing. Similarly, there are others with normal brain scans and normal cognitive functioning who have had concussions (Hofman et al., 2001; Hughes et al., 2004; Kurča, Sivák, \& Kučera, 2006; Lewine et al., 2007; Ling, Marshall, \& Moore, 2010), stymying confidence in a reliably measurable nexus between distal concussion history and "organic disturbances" measured by brain scanning, at any point in time, or cognitive testing, extending beyond the immediate/acute phase following a concussion.

The same problems with traditional, structural brain scan methods exist with the newer, "exotic" brain scan techniques, which include functional magnetic resonance imaging (fMRIs), single photon emission computed tomography (SPECT), and magnetoencephalography (MEG). Namely, if there is no reference point (e.g., a control group for researchers or knowing what the individual patient's brain looked like before the injury for clinicians), one cannot confidently opine in a legal arena that the abnormal brain scan was caused by the concussion. Also problematic with brain scan techniques is a higher false-positive rate (Genovese, Lazar, \& Nichols, 2002; Lieberman \& Cunningham, 2009), meaning an increased likelihood of artifactual evidence of brain damage when using these techniques. Moreover, some of the studies in this area fail to carefully and accurately characterize brain injury severity. For example, Grover et al. (2018) published results showing altered callosal sodium in mTBI patients but did not provide a definition of mTBI anywhere in their article. Meanwhile, the description of their brain scanning methods is extremely detailed, leaving little question about the scientific nature of the study: "Sodium $\left({ }^{23} \mathrm{Na}\right) \mathrm{MRI}$ scans were performed on a clinical 3T Scanner (Magnetom Prisma; Siemens, Erlangen, Germany) with a custom-built 8-channel dual-tuned $\left(1 \mathrm{H}^{-23} \mathrm{Na}\right)$ transmit/receive head array coil” (p. 2201). But these authors then grossly misrepresented the epidemiological data on mTBI by asserting that "Mild traumatic brain injury (mTBI) is the leading cause of death and disability in the United States and worldwide, with approximately 42 million cases annually" (p. 2200). By combining highly technical, scientific descriptions of brain scanning methodology with incomplete and inaccurate information on $\mathrm{mTBI}$, some researchers add little more than confusion to the knowledge base. In contrast, others (e.g., Bigler \& Maxwell, 2012; Hofman et al., 2001; Hughes et al., 2004; Kurča et al., 2006; Lewine et al., 2007; Shin et al., 2017; Wäljas et al., 2015; Yuh et al., 2014) are diligently working toward a more thorough understanding of neurobiological changes caused by mTBI, while also acknowledging the limitations of brain scanning methods. As stated previously, this important research may someday lead to reliable methods for correlating different types of intracranial bleeds (e.g., bleeds that invade parenchyma versus those that do not) with different long-term outcomes. At present, no such methods are available, so all intracranial bleeds tied to $m T B I$ are characterized as complicated-mild TBIs.

Lange, Iverson, Brubacher, Mädler, and Heran (2012) summarized this literature as follows: "Despite the assumed association between [concussions] and postconcussion symptoms, there is little neuroradiological evidence suggesting a direct causal link" (p. 189). Lange et al.'s statement is further buttressed by other more recent research, which has not found strong associations between postconcussion symptoms and abnormalities on computed tomography (CT) or structural MRIs (Dikmen et al., 2017; Wäljas et al., 2015), a theme also 
present in recent work done on plasma Tau and Amyloid-beta42 (Gill, French, Lange, Lippa, \& Brickell, 2018). In fairness, recent scientific investigation (e.g., Kulbe \& Geddes, 2016; Papa et al., 2013; Shin et al., 2017) may eventually lead to breakthroughs that change the current state of the science. At present, however, brain scanning and biomarker methodology remain of questionable reliability among those known to only have an mTBI, which is of particular relevance in medicolegal/forensic settings where evidentiary rules discourage the introduction of unreliable and misleading information.

In short, neuropsychological methods, while reliable and valid measures of cognitive constructs, are not particularly effective at reliably measuring brain trauma (organicity) in those with a remote history of concussion, but the same limitation holds for neuroradiological and biomarker methods. This means that the part of the foregoing ICD-10-CM definition of postconcussional syndrome involving organic problems engenders false expectations because there is no reliable way of establishing a causal link between concussion history and organic changes using neuropsychological, neuroradiological, or biomarker methods.

\section{Psychological Contributions to Symptom Expression Following $\mathrm{mTBI}$}

The ICD-10-CM definition of postconcussional syndrome also includes the term "psychogenic," which, like organicity, has shortcomings, although it is still in use, including among neurologists who encounter seizures with non-physiogenic causes. Despite its continued use, "psychogenic" is a term often used to imply that there is no tangible "medical" explanation for the symptoms; rather, the symptoms are considered psychological in origin. Among some professionals, this conceptualization can imply that the person's symptoms are less legitimate because they lack medical explanation, which is troublesome insofar as (a) symptoms caused by psychological forces are taken less seriously, (b) the person experiencing the symptoms is blamed for not having a real "medical" problem, and/or (c) the person experiencing the symptoms feels they have been stripped of a valid explanation for their difficulties.

Counterintuitively, however, symptoms caused entirely by psychological forces can sometimes be worse than those brought about by tangible, "medical" causes. Psychogenic non-epileptic seizures (PNES; Benbadis, 2005; Benbadis, Blustein, \& Sunstad, 2000; Gillig, 2013; Pritchard \& Hopp, 2014; Reuber et al., 2003), also historically called "pseudoseizures," represent a good example of a disorder with medically unverifiable causes but devastating consequences. Whereas a seizure involves abnormal electrical discharge within the brain that can be measured with electroencephalogram (EEG), PNES is believed to be a complicated result of both psychological and unmeasurable physiogenic forces, possibly caused by "[g]reater functional connectivity of limbic regions influencing motor preparatory regions during states of arousal" p. 1526 (Voon et al., 2010).

To this point, one study reported that approximately $20 \%$ of those with suspected seizure disorders referred to specialty epilepsy clinics for more in-depth neurological assessment and diagnostic workup end up having PNES (Pritchard \& Hopp, 2014). Similarly, it is known among neurologists that some patients have both physiogenic and psychogenic seizures (Chen \& LaFrance Jr, 2016), while others have drugresistant forms of physiogenic epilepsy (Nair, 2016), all of which makes diagnosis and management considerably more challenging. Again, contrary to what might be expected, many patients with PNES actually have poorer long-term outcomes than patients with medically verifiable seizures (Pritchard \& Hopp, 2014), demonstrating the power of psychological forces. Another, even more extreme, instance of psychological forces causing bad outcomes is what some researchers term "psychogenic death" (Leach, 2018), a condition where trauma survivors become so engulfed in negative thinking following the traumatic event that they shut down and die for no medically verifiable reason. In contrast, Tyson et al. (2018) recently found that patients with PNES have higher cognitive functioning than those with epilepsy, so concluding that PNES always translates into worse functioning is unsupported.

Nonetheless, as the foregoing examples highlight, persons experiencing symptoms with psychological origins are not always attention-seeking individuals whose presentation is faked or exaggerated; these are often people who, for psychological and unmeasurable physiogenic reasons, suffer troubling episodes that can be more limiting and debilitating than medically verifiable conditions. However, because the symptoms have "psychogenic" roots, the disorder is often not taken as seriously by healthcare professionals to the detriment of the patient. Therefore, it is important to emphasize that symptoms with psychological/psychogenic roots can be very serious; similarly, by clearly identifying the origin of the symptoms as psychological, the appropriate (i.e., psychological/educational) treatment can be implemented. Unfortunately, because the postconcussional syndrome diagnoses mixes physiogenic (i.e., medically verifiable) causes with psychologically based (i.e., medically unverifiable) causes, there is an increased likelihood that purely psychological forces will gain impetus because the patient is told their symptoms are, at least partially, driven by physiogenic forces. In contrast, if these patients were correctly informed from the outset that their persisting symptoms are (a) psychological in origin and, perhaps more importantly, (b) amenable to psychological intervention (McCrea et al., 2009; Minderhoud, Boelens, Huizenga, \& Saan, 1980; Mittenberg \& Burton, 1994; Ponsford, 2014; Ponsford, 2005; Ponsford et al., 2001; Ponsford et al., 2002; Wade, King, Wenden, Crawford, \& Caldwell, 1998), the 
patient would be held to task, but also empowered, an approach recommended by the WHO Collaborating Centre Task Force on mTBI (Borg et al., 2004):

The evidence supports a minimal educational strategy that also promotes return to activity as soon as possible. There is no evidence for routine administration of intensive assessment and intervention to minimize persisting complaints in MTBI. (p. 83)

\section{Intentional Symptom Production}

To diagnose postconcussional syndrome, the ICD-10-CM allows the clinician to rely on "subjective physical complaints," along with evidence of "cognitive, emotional, and behavioral changes." However, this creates difficulties because it does not account for scenarios where the patient is intentionally fabricating or exaggerating symptoms to achieve an external goal (e.g., malingering) or otherwise fabricating or exaggerating symptoms (i.e., feigning and dissimulating) to obtain attention from healthcare professionals or to avoid work, school, military service, or other responsibilities (Rogers, 2008; Rogers \& Bender, 2013; Rogers \& Shuman, 2006; Vore, 2007). Therefore, postconcussional syndrome diagnoses that are made without concurrent empirical evidence of valid selfreport (Larrabee, 2012) may introduce clinical information of questionable trustworthiness. To appreciate the potential magnitude of this problem, consider a recent study by Lande and Williams (2013) in which only 1074 out of $28,065,568$ patients (about $0.5 \%$ ) were identified as intentionally deceptive using unstructured clinical judgment, whereas other studies involving validity tests reveal a much higher rate of invalid data: 58\% Armistead-Jehle (2010), 33 to 52\% (Denning \& Shura, 2017), 15 to 17\% (Frederick, 2000), 40\% (Larrabee, 2003), 38.5\% (Mittenberg, Patton, Canyock, \& Condit, 2002), 15\% (Rogers, Harrell, \& Liff, 1993), 16\% (Rogers, Sewell, \& Goldstein, 1994), 3.4\% (Ruff, Klopfer, \& Blank, 2016), 1 to $20 \%$ (Sharland \& Gfeller, 2007), 5 to $30 \%$ (Slick, Tan, Strauss, \& Hultsch, 2004), over 50\% (Wall, Graver, \& Shurak, 2013), 0 to $30 \%$ (Young, 2015), and 15 to $48 \%$ (Youngjohn, Burrows, \& Erdal, 1995). If scientific methods to detect invalid symptoms are not used, it is likely that lowquality evidence will come before factfinders, which holds for those diagnosing postconcussional syndrome without also testing for symptom and performance validity (Larrabee, 2012).

\section{Illusory Correlations}

Physical, cognitive, emotional, and behavioral problems are not specific to those who have sustained a concussion (Hung et al., 2014; Lagarde et al., 2014); many people who have no history of brain injury subjectively experience, and report to healthcare providers, physical complaints, along with cognitive, emotional, and/or behavioral symptoms (Lees-Haley \& Brown, 1993). Put another way, there is an illusory correlation (Borum, Otto, \& Golding, 1993; Chapman \& Chapman, 1969; Faust \& Ahern, 2012) between these symptoms and a history of concussion, whereby the symptoms are misattributed to brain damage from the accident or injury. If the relationship between certain symptoms (e.g., physical, cognitive, emotional, and behavioral complaints) and a certain diagnosis (e.g., postconcussional syndrome) truly exists, the symptoms must occur more often among those with the diagnosis than they occur among those without the diagnosis (Faust \& Ahern, 2012):

Without this full set of facts-frequency of the symptom when the disorder is present and when it is not present- the determination cannot be made. Analyzing the frequency with which a symptom co-occurs with a disorder and occurs in the absence of a disorder is referred to as analysis of covariation. (p. 162)

An analysis of covariation between a cluster of symptoms and a diagnosis believed to represent that cluster of symptoms requires the creation of a $2 \times 2$ matrix (see Table 2). Specifically, the clinician crosses the diagnosis variable comprising two levels (i.e., diagnosis present versus diagnosis absent) with the sign or symptoms variable comprising two levels (i.e., symptoms present versus symptoms absent). In doing this, the result is four cells in the matrix.

Evidence of a true relationship between the symptoms and the diagnosis comes from filling in all four of the cells, A, B, C, and D. For example, if, as is the case with postconcussional syndrome, there are many people experiencing physical, cognitive, emotional, and behavioral complaints who have never had a concussion (cell C), it is harder to assert a causal relationship between concussion and the symptoms of postconcussional syndrome. Conversely, if the only people with the symptoms have a recent history of suffering a concussion (cell A), it is easier to assert a causal relationship between concussion and the symptoms of postconcussional syndrome. In practice, healthcare workers have a biased sample, meaning that most of the people they encounter have symptoms. It is,

Table 2 Covariation table

\begin{tabular}{lll}
\hline & Symptoms present & Symptoms absent \\
\hline Concussion present & A (50) & B (50) \\
Concussion absent & C (450) & D (450) \\
\hline
\end{tabular}

Clinicians naturally over focus on cell A, without considering cells B-D 
therefore, a short, convenient jump from having the symptoms to being given the diagnosis (Faust \& Ahern, 2012):

Clinicians typically confine their practices to individuals with apparent abnormalities or problems, and thus they often cannot form adequate estimates of how often the "symptoms" they observe among abnormal individuals also occur among normal individuals....Readers may be familiar with early work on the use of MRI, which seemed to suggest that certain findings obtained with symptomatic individuals explained their problems or demonstrated abnormality, only to find through subsequent studies with normal individuals that such findings were also common, if not equally common, in nonsymptomatic individuals. The nature of the relationship, or the lack of a relationship, was not apparent until studies were conducted both with individuals considered abnormal and individuals considered normal. (p. 163)

To bring these important concepts to life, a numerical example is helpful. A researcher collects a random sample of 1000 individuals from the community, ascertains how many had a concussion at least 6 months before the study (since postconcussional syndrome is, by definition, a problem that extends beyond the acute phase, immediately after the injury), and finds that 100 individuals (10\%) had a concussion. The researcher also ensures that none of these 100 individuals had intracranial bleeding following the concussion. The researcher then has all 1000 individuals fill out a short questionnaire designed to measure symptoms of postconcussional syndrome (e.g., headaches, dizziness, cognitive, emotional, and behavioral symptoms) and finds that 850 individuals (85\%) in the sample experience some of these symptoms. Next, the researcher crosstabulates the concussion history variable (present/absent) with the symptoms variable (present/absent), exactly like Table 2, and finds that half of those with a concussion history have symptoms of postconcussional syndrome and half do not. Similarly, the researcher finds that half of those who never had a concussion experience symptoms and half do not. In order for concussion history to relate to symptoms, cell counts (i.e., A, B, C, and D) must deviate from what is expected, which can be statistically evaluated using the chi-square test. Using these numbers, the chi-square statistic is 0.011 , with a $p$ value of .916, which is not significant. In simple terms, there is absolutely no relationship between concussion history and the symptoms of postconcussional syndrome, using this hypothetical, numerical example.

What is important to appreciate here is that clinicians (and attorneys representing plaintiffs asserting injury from a concussion) only have access to cell $\mathrm{A}$, which sets the stage for circular logic, to be explained more in the next section. Therefore, it is crucial that clinicians (and plaintiff attorneys) seriously consider alternative explanations for the data, which, through analysis of covariation, expands the analysis by considering the entire picture.

\section{Alternative Causes of Symptoms Underlying a Postconcussional Syndrome Diagnosis}

Ideally, healthcare professionals will seriously consider alternative, viable explanations for the postconcussion symptoms, other than the concussion and a postconcussional syndrome diagnosis. Some of the more salient alternative explanations for postconcussion symptomatology include the following: (1) simply being a healthy, normal person (Iverson \& Lange, 2003); (2) being a regular outpatient with other psychological problems (Fox, Lees-Haley, Earnest, \& Dolezal-Wood, 1995); (3) litigation (Lees-Haley \& Brown, 1993; Weissman, 1990); (4) posttraumatic stress disorder (Flynn, 2010; Foa, Cashman, Jaycox, \& Perry, 1997); (5) orthopedic injuries (Mickevičiene et al., 2004); (6) chronic pain (Iverson \& McCracken, 1997); (7) whiplash (Sullivan, Hall, Bartolacci, Sullivan, \& Adams, 2002); (8) pre-injury personality disorders (Hibbard et al., 2000); (9) the manner in which symptoms are elicited from the patient (Iverson, Brooks, Ashton, \& Lange, 2010); (10) lack of sleep or undiagnosed sleep apnea (Stranks \& Crowe, 2016); (11) depression (Basso, Miller, Estevis, \& Combs, 2013; Basso \& Bornstein, 1999; Iverson, 2006; Flynn, 2010); (12) anxiety (Meares et al., 2011); (13) recent substance use (Hall \& Degenhardt, 2009); (14) medication side effects (Barker, Greenwood, Jackson, \& Crowe, 2004; Curran, 1991; de Gage et al., 2012; Ortinski \& Meador, 2004; Pariente, de Gage, Moore, \& Bégaud, 2016; Ruxton, Woodman, \& Mangoni, 2015); (15) hunger; (16) illnesses (e.g., having a cold); and other possibilities. In considering the full range of alternative explanations for postconcussion symptoms, unsophisticated circular logic is avoided, as the following examples illustrate:

"Bipolar disorder can cause inflated self-esteem, talkativeness, increases in goal-directed behavior, and racing thoughts. This patient has inflated self-esteem, talkativeness, increases in goal-directed behavior, and racing thoughts. Therefore, this patient has bipolar."

"Postconcussional syndrome consists of headaches, dizziness, cognitive problems, emotional problems, and behavioral changes. This patient had a concussion and has headaches, dizziness, cognitive problems, emotional problems, and behavioral changes. Therefore, this patient has postconcussional syndrome." 
Many mental health diagnoses, including postconcussional syndrome, are defined in a way that seduces laypersons and some clinicians to think illusory correlations reflect causality. While this does not hold for diagnoses requiring more than the presence of certain symptoms (e.g., Intellectual Disability involves an IQ score; "strep throat" involves a throat culture for streptococcus bacteria), it remains a limitation for postconcussional syndrome and related diagnoses that hinge entirely on subjective report of symptoms that could have alternative causes and/or be present among those without functional problems. As was the case with the now-discarded diagnostic criteria for "postconcussional disorder" (Fox, 2017) found in the Diagnostic and Statistical Manual of Mental Disorders, fourth edition, text revision (DSM-IV-TR; American Psychiatric Association, 2000), the ICD-10-CM definition of postconcussional syndrome is defined in a way that increases the odds of diagnosing those whose postconcussion symptoms originated elsewhere. This problem has been largely fleshed out in the concussion literature (Gouvier, Cubic, Jones, Brantley, \& Cutlip, 1992; Gouvier, Uddo-Crane, \& Brown, 1988; Gunstad \& Suhr, 2004; Iverson \& Lange, 2003; Mittenberg, DiGiulio, Perrin, \& Bass, 1992; Wong, Regennitter, \& Barrios, 1994), wherein it is evident that many persons without a history of concussion experience the same symptoms that are found in the postconcussional syndrome diagnostic criteria at very high base rates, which leads to another diagnostic problem, illustrated in the next section.

\section{Base Rates}

Related to the covariation matrix in Table 2 is the important concept of base rate, which, in this context, simply means the percentage of those having had a concussion who truly have postconcussional syndrome. The base rate is theoretically represented by a different $2 \times 2$ matrix than the one described previously. In this $2 \times 2$ matrix (see Table 3 ), the clinician crosses a diagnosis variable comprising two levels (i.e., diagnosis given versus diagnosis not given) with a reality variable

Table 3 Base rate $\mathrm{X}$ diagnosis table

\begin{tabular}{lll}
\hline & Disorder truly present & Disorder truly absent \\
\hline Diagnosis given & A (true positives; 17) & B (false positives; 300) \\
Diagnosis not given & C (false negatives; 8) & D (true negatives; 675) \\
\hline
\end{tabular}

Cross-tabulating base rate information (columns) with diagnostic information (rows) yields sensitivity, specificity, and overall diagnostic accuracy statistics (e.g., Youden's $J$ index [sensitivity + specificity -1 ] or a diagnostic odds ratio $[\mathrm{A} / \mathrm{B}] /[\mathrm{C} / \mathrm{D}])$ comprising two levels (i.e., disorder truly present versus disorder truly absent). In doing this, the following four cells are created in the matrix.

The base rate is computed as follows: $(\mathrm{A}+\mathrm{C}) /(\mathrm{A}+\mathrm{B}+\mathrm{C}+$ D). Put simply, the base rate is the percentage of those truly known to have the disorder. The lower the base rate for a disorder, the harder it is to correctly give the diagnosis. In other words, if very few people in the population ever get postconcussional syndrome, the methods used to diagnose postconcussional syndrome may not work. Under these circumstances, using the base rate as the primary guide for decision-making is preferred to other decision-making guides (e.g., unstructured clinical judgment), which are likely to be far less accurate.

The base rate for postconcussional syndrome is not known with certainty because not all people who sustain a concussion report it to healthcare professionals (Sosin, Sniezek, \& Thurman, 1996). It has been estimated, however, to be extremely low. Specifically, McCrea reported that the base rate for developing postconcussional syndrome among those who had a concussion to be somewhere between $1 \%$ and $5 \%$ (McCrea, 2008).

Assuming that the base rate for postconcussional syndrome is in the middle of these two numbers, at $2.5 \%$, a numerical example is helpful to make an important point about diagnostic accuracy. A researcher identifies 1000 individuals who experienced a concussion at least 6 months ago to allow time for recovery of cognitive functions beyond the acute phase. Next, the researcher ensures that none of these individuals had intracranial bleeding following their concussion to ensure that none of these individuals had a complicated-mild TBI. Then, the researcher uses the ICD-10-CM to diagnose postconcussional syndrome in this sample of 1000 individuals and finds that 850 individuals in the sample $(85 \%)$ experience symptoms of postconcussional syndrome (e.g., headaches, dizziness, cognitive, emotional, and behavioral symptoms). So the researcher diagnoses these 850 individuals with postconcussional syndrome. Using the base rate of $2.5 \%$ for postconcussional syndrome, it is easy to see that the researcher has made a mistake because they diagnosed $85 \%$ of the sample with postconcussional syndrome, which is much higher than expected. The researcher realizes this and decides to develop a diagnostic test to improve diagnostic accuracy. Of the $85 \%$ previously diagnosed with postconcussional syndrome, the researcher collects more extensive historical information and learns that most of these individuals experienced some symptoms before the concussion, while others experience some symptoms for other reasons (e.g., posttraumatic stress disorder, pain-related sleep disturbance, pain from orthopedic injuries, side effects from medication prescribed for orthopedic injuries, increased posts-accident substance use, depression, anxiety, and so on). Through more meticulous history taking, interviewing of family members, and review of 
medical records, the researcher is able to identify 25 individuals most likely to truly have postconcussional syndrome, which comports with the base rate of $2.5 \%$. As a final step, the researcher uses their new diagnostic test to see how well it correctly identifies the 25 individuals believed by the researcher to truly have postconcussional syndrome.

As shown in Table 3, the test correctly diagnosis 17 of the 25 individuals with postconcussional syndrome (sensitivity = $\mathrm{A} /[\mathrm{A}+\mathrm{C}]=.68$ ). The researcher also finds that the test correctly does not diagnose 675 of the 975 individuals without postconcussional syndrome ( specificity $=\mathrm{D} /[\mathrm{B}+\mathrm{D}]=.69$ ) . To simplify all of this information on the new diagnostic test, the researcher combines the test's sensitivity (i.e., those correctly identified by the test as having postconcussional syndrome) with the test's specificity (i.e., those correctly identified by the test as not having postconcussional syndrome) to get an overall index of the new test's diagnostic accuracy. This is accomplished by adding sensitivity to specificity and subtracting a value of 1 , to get a Youden's $J$ index of .37 , which tells the researcher the probability that they made the right diagnostic decision using their new test. While using the researcher's test is better than simply using ICD-10-CM diagnostic criteria, which led to a very high false-positive rate (i.e., $85 \%$ of the sample was diagnosed with postconcussional syndrome, compared to a base rate of $2.5 \%$ ), the new test is still not more accurate than using the base rate, nor does it improve decision-making over chance levels (i.e., being right $50 \%$ of the time). In other words, by simply using the base rate, one is going to be correct $97.5 \%$ (i.e., $100 \%-2.5 \%=97.5 \%$ ) of the time, which is much better than being right $37 \%$ of the time.

To get an alternative overall index of the test's diagnostic accuracy, the researcher then computes a diagnostic odds ratio $([\mathrm{A} / \mathrm{B}] /[\mathrm{C} / \mathrm{D}]=4.78)$. This number allows the researcher to conclude that someone diagnosed with postconcussional syndrome, using the researcher's new test, is 4.78 times more likely to truly have postconcussional syndrome than if the test did not diagnose postconcussional syndrome. However, only armed with the base rate, the researcher is over 40 times more likely to be right if they conclude that any given person in the sample of 1000 does not have postconcussional syndrome.

Several main points need to be emphasized. The rate at which a disorder occurs, called the base rate, influences how likely a clinician is to correctly diagnose the disorder. Clinicians are much more likely to correctly diagnose disorders that are extremely common (i.e., that have a high base rate); likewise, they are much less likely to correctly diagnose disorders that are rare (i.e., that have a low base rate). Even among those who firmly believe in postconcussional syndrome, it is agreed that the base rate for this disorder is extremely low, meaning the clinician making this diagnosis must employ diagnostic methods that outperform the low base rate. Lacking compelling evidence for such diagnostic methods, the clinician is likely to make more diagnostic errors than correct diagnoses, if they diagnose postconcussional syndrome. As will be described next, there is compelling scientific justification to question the very existence of postconcussional syndrome, meaning an even lower base rate and, correspondingly, an increased diagnostic error rate for anyone making this diagnosis.

\section{The Base Rate of Postconcussional Syndrome}

Whereas McCrea (2008) reported a base rate for postconcussional syndrome of 1 to $5 \%$, other researchers have concluded that postconcussional syndrome, in effect, does not exist. For example, Larrabee (2005) concluded:

Cumulative research on the outcome of a single, uncomplicated MTBI shows that neuropsychological deficits may persist for up to 3 months, but the norm is full recovery, with no long-term residual deficits... (p. 216)

There is increasing evidence that questions the validity of the [postconcussional syndrome] symptom constellation. To qualify as a syndrome, a condition must demonstrate a set of specifically associated symptoms broadly present in persons who have the condition and absent in those who do not have it... (p. 222)

Boone (2013) reached a stronger conclusion:

...research does not support the view that long-term cognitive abnormalities are caused by [concussion] in all or even a small subset of patients. Rather, chronic symptom report and underperformance on cognitive measures are driven by other factors. (p. 251)

And, more recently, the following assertions were promulgated by Rohling, Langhinrichsen-Rohling, and Axelrod (2017):

Thus, as we have reviewed, state-of-the-art research has definitively demonstrated that a person with a single mTBI has no long-term cognitive or psychological deficits. This was also the conclusion reached by the Committee on Traumatic Brain Injury: Board of health Care Services (Institute of Medicine, 2006), the WHO (Carroll et al., 2004), the American Medical Association (Giza et al., 2013), the Department of Veterans Affairs, the Department of Defense (Research Advisory Committee on Gulf War Veterans' Illness, 2008), as well as six meta-analyses... which represent hundreds of studies and thousands of individuals. (p. 153)

All of this information is important given that base rates influence diagnostic accuracy, as fleshed out above. In other words, if the true rate of postconcussional syndrome is even 
closer to 0 than some of the literature suggests, then clinicians are even less likely to correctly diagnose it, which is a unique problem in legal arenas because factfinders are seeking reliable and trustworthy evidence that will enhance, not dilute (Nisbett, Zukier, \& Lemley, 1981), their decision-making.

\section{latrogenesis}

The power of authority commanded by healthcare professionals who diagnose postconcussional syndrome can trigger or fuel psychological mechanisms that contribute to or underlie the postconcussion symptoms. Put plainly, the healthcare professional making this diagnosis can literally bring the diagnosis to life and spark avoidable diagnostic momentum (Croskerry, 2002), thereby having an iatrogenic (i.e., harmful) effect on the patient. This phenomenon has been studied and is sometimes called response expectancy (Suhr \& Wei, 2013), a subtype of which is diagnosis threat (Suhr \& Gunstad, 2002). Diagnosis threat goes as follows (Suhr \& Wei, 2013):

...culture and society are sources of information about disease and illness, including typical symptoms, causes, prognoses, and treatments, and effects of an illness on social roles and responsibilities...disease-specific beliefs may be learned through not only personal experience but also the suggestions of others (news media, public health announcements, physician suggestion) and can even be learned through observations...In other words, when one is given diagnosis $\mathrm{X}$ and then reads about diagnosis $\mathrm{X}$, hears about it on television, attends support groups for diagnosis $\mathrm{X}$, and meets others with diagnosis $\mathrm{X}$, etc., this can create response expectancy templates that include how X might affect cognitive abilities... (p. 189)

It is important to emphasize that clinicians diagnosing postconcussional syndrome are not intentionally trying to harm patients. Rather, they are applying a diagnosis that, as underscored here, has not been scrutinized enough. Unfortunately, however, a well-intentioned clinician who applies the postconcussional syndrome diagnosis to certain vulnerable individuals runs the risk of hindering rather than helping, a scenario frequently encountered by any busy neuropsychologist and illustrated in Ervin White v. Guest Services, Inc. (Court of Appeals of North Carolina, 2018), which is reviewed below (see "Opining with a Reasonable Degree of Certainty About Postconcussional Syndrome”).

\section{Alternative Diagnostic Options}

Despite its name, postconcussional syndrome is a condition lacking a specific cause. As proposed by Bush and Myers
(2013), postaccident syndrome or postinjury syndrome might be better terms to encompass the complex interaction of physical, cognitive, and emotional symptoms that emerge following accidents or injuries that include a concussion. Until postconcussion symptoms can be causally linked to concussion in a reliable manner, it is better for clinicians to not diagnosis postconcussional syndrome, especially clinicians operating in the forensic arena, and to instead diagnose relevant conditions that are more likely to be driving the reported symptoms. For example, when the evidence supports a valid presentation, use of a psychological disorder such as posttraumatic stress disorder or somatic symptom disorder, or sleep or pain disorders, may be helpful. Focus should also be directed to neurological problems other than the concussion (postaccident headache, back pain, neck pain, etc.). And when a convergence of evidence suggests that the presenting problems are intentionally exaggerated or fabricated, malingering or a factitious disorder may be good diagnostic options. Finally, part of the diagnostic process among those suffering an accident or injury that includes a concussion is to properly educate them about what to expect, a topic addressed in more detail in the following section.

\section{Ethical Considerations}

Experience suggests that most healthcare professionals attempt to apply the most accurate diagnoses to their patients. However, perhaps due to longstanding habits, unquestioned practice, or reimbursement requirements, use of some diagnoses outlives their usefulness. At present, healthcare professionals who use the ICD-10-CM to diagnosis postconcussional syndrome may, despite good intentions, find their actions heavily scrutinized when viewed through the lens of current mTBI research and evidence-based practice. And insofar as healthcare professionals apply a diagnosis of postconcussional syndrome in order to justify ongoing subsequent services (e.g., weeks or months of costly rehabilitative therapy), they risk even more scrutiny.

Ironically, because the postconcussional syndrome diagnosis has been widely used for so long, clinicians who stay abreast of the developing mTBI literature may find themselves under attack by patients if they do not embrace the postconcussional syndrome explanation for the patient's symptoms. Patients trust their healthcare providers and, understandably, invest themselves in the significance of a diagnosis. Removing a particular diagnostic explanation forces those involved (i.e., the patient, family members, friends, existing healthcare professionals, attorneys) to reconceptualize how they have come to understand the patient's difficulties, which can disrupt the equilibrium. While some patients are extremely grateful to learn that they will recover from an mTBI, others can become extremely dissatisfied with the new explanation for their symptoms. And this frustration can be directed toward clinicians, sometimes in the form of 
complaints made to insurance companies, licensing boards, and so forth. For this reason, healthcare professionals who challenge pre-existing postconcussional syndrome diagnoses should do so respectfully, cautiously, and from an evidencebased educational perspective, while remaining prepared for various forms of blowback.

Primary ethical goals for neuropsychologists, as well as other healthcare providers (psychologists, psychiatrists, neurologists, nurse practitioners, physician assistants, etc.), include providing beneficial information and services and striving not to offer information or services that will likely be harmful to patients. By incorrectly conceptualizing persistent postconcussion symptoms as resulting from a remote concussion, clinicians can be harmful by hindering patients' recoveries. In contrast, providing education and treatment from an evidence-based biopsychosocial perspective can promote a patient's understanding and wellbeing (Borg et al., 2004; Ponsford, 2014, 2005; McCrea et al., 2009; Minderhoud et al., 1980; Mittenberg \& Burton, 1994; Ponsford et al., 2001, 2002; Riechers \& Ruff, 2010; Wade et al., 1998). Moreover, in litigation, such evidence-based information can assist factfinders to arrive at just legal decisions.

\section{Legal Considerations}

Four legal issues stand out as having particular relevance for mTBI cases: (1) a lack of clarity regarding a definition of socalled reasonable medical (psychological, neuropsychological, or scientific) certainty, (2) the extent to which healthcare professionals can opine to a reasonable degree of medical (psychological, neuropsychological, or scientific) certainty about the presence of postconcussional syndrome, (3) inconsistent interpretations of postconcussional syndrome by the courts, and (4) admissibility of postconcussional syndrome opinion evidence. These four subjects are sequentially unpacked in the following paragraphs.

\section{Problems with Reasonable Medical Certainty}

According to Black's Law Dictionary (Bryan, 2009), "reasonable medical probability" is the same as "reasonable medical certainty" and both can be defined as "a showing that the injury was more likely than not caused by a particular stimulus, based on the general consensus of recognized medical thought." Whereas Black's Law Dictionary attempts to give a clear definition of "reasonable certainty," other commentators challenge this way of communicating information. For example, Melton et al. (2017) questioned the use of this wording on the basis that it oversimplifies matters by replacing quantitative, probabilistic statements with qualitative phrasing that may have different meanings to different people: ...even if it heightens the discomfort of both clinicians and courts, clinicians involved in the legal process should aim to think like scientists and give an accurate picture of probabilistic findings. This general admonition is appropriate even in jurisdictions that attempt to transform probabilistic judgments into certain facts by applying the standard of "reasonable medical (or psychological or scientific) certainty" when deciding the admissibility of expert testimony. Both courts and professionals are likely to have idiosyncratic subjective judgments of "reasonable certainty"; moreover, even "uncertain" opinions may still be relevant and of assistance to the trier of fact, provided that the conclusions have some probative value and are not prejudicial. Most important, the standard of reasonable certainty may itself result in prejudicial opinions, because the "certainty" standard masks the fact that underlying judgments are merely probabilistic. (pp. 12-13)

These same authors also discouraged clinicians from being pressured into rendering opinions that are not supported by the state of scientific knowledge and warned clinicians about making statements to a reasonable medical certainty.

In his discussion of the matter, Miller (2006) raised more questions about the use of the phrase "reasonable medical/ psychological/neuropsychological/scientific certainty":

The phrase "reasonable certainty" has become embedded in the legal world of expert testimony, the version used with physicians being "reasonable medical certainty," and with psychologists usually "reasonable scientific certainty." Such experts are required to sanctify their opinions in court in virtually every jurisdiction by uttering the magic words before their testimony will be admitted as expert. Unfortunately, the phrase has no consistent legal meaning [and] often no specified meaning at all. Courts differ as to its definition, if they define it at all. (p. 273)

This author concluded his in-depth discussion of reasonable medical certainty with some valuable recommendations. If the term has been clearly defined in one's jurisdiction, the healthcare expert must learn and use that definition. If it has not been clearly defined, the expert is encouraged to create and use their own clear definition. And if requested to opine to a reasonable medical certainty, experts are encouraged to respectfully ask the requesting attorney to clarify exactly how they define "reasonable medical certainty." For more valuable information on "reasonable medical certainty," including discussion of jurisdictional variability, Miller (2006) is extremely helpful.

Rohling, Axelrod, and Langhinrichsen-Rohling (2017), like Black's Law Dictionary, recently defined reasonable medical certainty. However, unlike the recommendation in Black's 
Law Dictionary that the term reflect "more likely than not" (i.e., anything above 50\% certain), they suggested that reasonable medical certainty should mean an outcome that is $75 \%$ to $92 \%$ likely to be accurate. Rohling, Axelrod, and Langhinrichsen-Rohling (2017) concluded their helpful discussion by suggesting that "reasonable degree of medical certainty" can be translated, in scientific language, to mean a statement that balances false-positive conclusions with falsenegative conclusions:

One issue to address when addressing levels of certainty is statistical power. Cohen (1988) recommended for common research questions that a beta-to-alpha ratio should be $4: 1$. This means that it is 4 times more likely that a type II error will be made (i.e., assume a condition is not present when in fact it actually exists) than it is that a Type I error will be made (i.e., assume a condition is present when in fact it is not)...if one is asked to apply the standard of "to a reasonable degree of medical certainty," this is more consistent with a beta-to-alpha ratio of 1:1." (p. 4)

In emphasizing a beta-to-alpha ratio of 1:1, Rohling, Axelrod, and Langhinrichsen-Rohling (2017) are saying that "reasonable degree of certainty" means the expert is making a causative probability statement in a legal setting (e.g., a deposition, a preliminary hearing, a trial) that equally takes into consideration (a) the probability of erroneously asserting a causal link (alpha; a type I error; false positive error) and (b) the probability of erroneously rejecting a causal link (beta; a type II error; false negative error).

What should be evident from the foregoing discussion is that there remains a lack of clarity regarding a definition of reasonable medical/psychological/neuropsychological/scientific certainty and what to do about it. Similarly, not all clinical decision-making errors (i.e., false positive versus false negative errors) are of equal significance. Therefore, clinicians adopting this phrasing in the legal arena should do so with an awareness of these challenging and unresolved issues, rather than barging forward with bold, unsupported statements about what is causing what. Given the wobbly scientific foundation of postconcussional syndrome, asserting a causal link between a concussion and postconcussional syndrome falls short of the reasonable medical certainty standard, whichever of the various standards is used.

\section{Opining with a Reasonable Degree of Certainty About Postconcussional Syndrome}

It is not hard to quickly encounter recent civil and criminal cases, wherein mental health experts are actively opining with a reasonable degree of certainty about postconcussional syndrome and its deleterious effects. In Ervin White v. Guest
Services Inc. (Court of Appeals of North Carolina, 2018), plaintiff, Ervin White, "turned his head and struck a corner of a wooden storage rack." An employee found Mr. White "lying on the ground," so he was transported to a hospital, "where he reported suffering from an acute headache and back pain." Mr. White was advised by hospital staff to not work and to seek treatment with a primary care provider. Four days later, Mr. White was seen by a physician assistant, who diagnosed a concussion and ultimately referred him to a neurologist, who saw Mr. White approximately 2 months after the concussion. The neurologist interpreted a brain MRI as showing "chronic small vessel changes or white matter changes, which could be age-related or post-traumatic" and diagnosed "post-concussive syndrome, post-traumatic migraines, and post-traumatic memory loss." The neurologist directed Mr. White to "stay out of work" for another 4 months and "later testified that plaintiff's complaints of headaches, mood issues, and memory and concentration issues were consistent with his physical examination and that plaintiff's complaints to a reasonable degree of medical certainty were causally related to plaintiff's 24 July 2015 injury." The neurologist also "wrote that plaintiff was permanently disabled [and that] he most likely was not going to get better."

In this case, Mr. White experienced an mTBI without any intracranial bleeding. Therefore, given the severity of his TBI, he should have also experienced a relatively quick and full recovery from any cognitive deficits he was experiencing, after getting beyond the acute/immediate phase of his recovery. Rather than being properly educated about this, however, his physician advised him to not work for many months and ultimately concluded, to a reasonable degree of medical certainty, that Mr. White was "permanently disabled" due, in part, to postconcussional syndrome, thereby doing exactly what Bauer (1997) urged neuropsychologists not to do.

In Matter of Williams (Supreme Court of Wyoming, 2018), a well operator, Richard Williams, applied for workers' compensation benefits following a work-related head injury that initially included brief LOC and a severe headache. Mr. Williams was Life Flighted from the accident to the Wyoming Medical Center in Casper, Wyoming, during which time "severe dizziness" and "hematoma to the basilar region" were documented in the Life Flight notes. Ultimately, Mr. Williams was diagnosed with "postconcussion syndrome and occipital hematoma," given pain medication and discharged. Four days later, he followed up with his primary care doctor and "reported decreased focus, increased anxiety, difficulty sleeping, and a recurring replay of the flash fire." Mr. Williams was then diagnosed with "situational anxiety," posttraumatic stress disorder, prescribed a benzodiazepine, and encouraged to participate in counseling. A month later, Mr. Williams was given a different benzodiazepine because the symptoms were getting worse and he was "excused from work for another week." At the same time, he was evaluated 
by another healthcare provider, who diagnosed him with "amnestic disorder due to a general medical condition."

About 1 month later, Mr. Williams' claim for workers' compensation benefits was denied on the basis that his injuries did not arise "out of and in the course of [his] employment on June 21, 2014." So he initiated a hearing, which was referred to the Office of Administrative Hearings (OAH). Approximately 3 months later, Mr. Williams was evaluated by a medical doctor and a "licensed clinical psychologist" over the course of 2 days. The medical doctor diagnosed "a post-concussive syndrome from his traumatic brain injury" and added, "I feel that Mr. Williams is not capable of working at his job at this time and I do not feel that he is capable of working at any job because of his emotional problems and memory and concentration issues", again going against Bauer's, 1997 advice. The neuropsychologist diagnosed the worker with "mild neurocognitive disorder due to traumatic brain injury with behavioral disturbance (behavioral disturbance includes irritability and reduced stress tolerance)," "depressive disorder due to traumatic brain injury," and "post-traumatic stress disorder." The neuropsychologist also made this conclusion: "it is my opinion within a reasonable neuropsychological certainty that the cognitive deficits noted on testing relate directly and solely to a Traumatic Brain Injury sustained in the work-related accident of June 21, 2014."

In this case, Mr. Williams sustained what was, in all likelihood, a complicated-mild TBI, given the "occipital hematoma." However, "within a reasonable degree of neuropsychological certainty," he was diagnosed with postconcussional syndrome, which is a diagnosis reserved for those having experienced an uncomplicated mild TBI (i.e., a concussion without intracranial bleeding), which is less serious. Had Mr. Williams' TBI been accurately characterized at the outset as having a complicated-mild TBI, the case may not have been appealed up to the Supreme Court of Wyoming. Moreover, had the more precise and scientifically supported diagnosis of complicated-mild TBI been applied, the opining expert could have relied upon the body of existing literature on outcomes following complicated-mild TBIs (Fay et al., 2010; Kashluba et al., 2008; Levin et al., 2008), thereby providing the factfinder(s) with helpful and trustworthy information.

In State v. Shierman (Supreme Court of Washington, En Banc, 2018), the Court reversed a guilty verdict in a death penalty case for a defendant who had been convicted of four counts of aggravated first-degree murder, in part, on the basis that he had "[p]ost-concussion syndrome" and that multiple concussions have a cumulative negative effect on cognitive functioning:

According to Dr. Connor, the earlier injuries were significant because they likely worsened the effects of the 1997 concussion: "It is well documented that multiple head injuries ha[ve] a cumulative effect such that in each subsequent injury, the negative impacts are often greater than would be expected from one head injury in isolation."

...it is possible that [the concussion] had an impact on subsequent mood problems and intensity of substance abuse. When Mr. Schierman was intoxicated, the brain injury may have contributed to worsening any problems with loss of inhibitions, interpreting his surroundings, and controlling anger/aggression.

While Dr. McClung did not testify that prior brain injury probably impaired Schierman's capacities, he did testify that it possibly impaired Schierman's capacities...Dr. McClung's testimony is therefore relevant mitigating evidence in the penalty phase. The cumulative effect of excluding all of this science in the penalty phase was not harmless.

State v. Shierman is relevant because it highlights a very recent example of postconcussional syndrome influencing legal outcomes and because it does not comport with scientific findings in this area. In contrast to Dr. Connor's probable assertions, and Dr. McClung's possible assertions, that capital defendant Shierman's history of multiple concussions diminished his mental capacity to intentionally murder four people, including two "young children," Boone (2013) summarized the research in this area as follows:

Some neuropsychologists have the belief that while a single concussion may not result in permanent cognitive sequelae, more than one in a person's lifetime does... But what does the literature say in regard to the effects of multiple concussion? Most investigations have found no relationship between number of concussions and cognitive test performance (Collie, McCrory, \& Makdissi, 2006; Guskiewicz, Mamrshall, Broglio, Cantu, \& Kirkendall, 2002; Iverson, Brooks, Lovell, \& Collins, 2006; Pellman, Lovell, Viano, Casson, \& Tucker, 2004). (pp. 241-242)

Boone also cited findings from Bijur, Haslum, and Golding (1996) as evidence that social and personal factors, not brain damage, explain why children experiencing multiple mTBIs score lower on tests of intelligence and academic achievement. Boone then cited a 2010 meta-analysis by Belanger, Spiegel, and Vanderploeg (2010), which concluded that the "overall effect of multiple mTBI on neuropsychological functioning was minimal $(\mathrm{d}=.06)$ and not significant" (p. 242). Similarly, Carone and Bush (2014) concluded that chronic traumatic encephalopathy (CTE) "may indeed exist," but added that CTE is likely to be caused by multiple factors, as opposed only to concussions associated with years of playing football. More recently, Rohling, Langhinrichsen-Rohling, and Axelrod (2017) asserted that the current research is not 
clear with regard to the cumulative effects of experiencing many mTBIs, but that the "vast majority" are not likely to have lasting symptoms.

While the current research supports the conclusion that multiple mTBIs separated by relatively long periods of time (e.g., weeks, months, or years) do not increase the likelihood that an individual will develop brain damage, future research may support a different conclusion. Moreover, it is important to emphasize that "multiple mTBIs" does not mean the same thing; that is, five mTBIs, each separated by weeks, months, or years, are likely to be less serious than 50 mTBIs, some of which were not separated by days, thereby increasing the odds of second-impact syndrome (i.e., death caused when a concussed brain gets re-injured before it has healed). Hence, the current state of knowledge with regard to "multiple mTBIs" is developing, despite some tentative conclusions. Therefore, it is concerning that some medical experts are actively opining to a reasonable degree of certainty that "It is well documented that multiple head injuries ha[ve] a cumulative effect...," when, in fact, it is not well documented that multiple concussions have a cumulative effect. Rather, the opposite is more likely, given certain parameters.

Because of (a) the myriad problems with postconcussional syndrome and (b) a vague legal definition of reasonable certainty, healthcare professionals opining with reasonable certainty on the presence of postconcussional syndrome are not coloring inside the lines of current scientific research. As is discussed in the next section, the inconsistencies regarding reasonable certainty and the diagnostic use of postconcussional syndrome also pervade the case law inasmuch as courts have interpreted injuries involving concussions/postconcussional syndrome in conflicting ways, adding confusion to this topic.

\section{Courts Handling of Postconcussional Syndrome}

Half a century ago, "postconcussion syndrome" was used by some clinicians to describe patients suffering through a weeklong coma, whereas today, the diagnosis is generally given after one has suffered a "mild" TBI. This diagnostic shift is reflected in case law. For example, Thompson v. Anderman (Supreme Court of New Mexico, 1955) involves a diagnosis of "post concussion syndrome" in a plaintiff who was "rendered totally unconscious from May 28th until June 2 nd" as the result of being in "...critical condition with a basal skull fracture, cerebral concussion, brain stem damage..." From this case, it is apparent that, in 1955, being in a coma for 5 to 6 days did not preclude a diagnosis of "post concussion syndrome," which would be inconsistent with usual and customary practice today.

Similarly, Durham v. Gulf Interstate Engineering Company (Supreme Court of New Mexico, 1964) involved a plaintiff who "suffered a moderately severe cerebral concussion with a possibility of an increased threshold tendency for epileptiform attacks." This case stands out today because describing a concussion as "moderately severe" runs afoul of the current medical vernacular in use to differentiate "mild," "moderate," and "severe" traumatic brain injuries: calling a concussion "moderately severe" makes a mild TBI seem on par with moderate or severe TBIs, which, as described previously, is not accurate. Additionally, it currently is not common practice to rate severities of concussion.

Two decades later, in Sanchez v. Molycorps, Inc. (Court of Appeals of New Mexico, 1985), the plaintiff "suffered brain damage with a post-concussion syndrome (organic personality syndrome) accompanied by chronic and severe headaches, dizziness and general difficulty in functioning, producing severe psychological reactions, including depression." In this 1985 case, the plaintiff's "postconcussive syndrome" diagnosis was based on him falling, hitting his head on a rail, but not losing consciousness, which is clearly at odds with the "post concussion syndrome" diagnosis in Thompson v. Anderman, decided 30 years earlier.

Four year later, in Bowles v. Los Lunas Schools (Court of Appeals of New Mexico, 1989), a woman was pushed off a platform, causing her to break a bone in her foot, suffer neck and back strain, and have "a concussion." But rather than attribute her deficits to postconcussional syndrome, the neuropsychologist in this case attributed the woman's cognitive difficulties to stress associated with the fall:

In Dr. Yeo's opinion, it was more probable than not that claimant's cognitive difficulties were not the result of the concussion but, rather, were secondary to the stress. While Dr. Yeo could not rule out brain damage entirely, it was more probable than not that there was no organic brain damage.

The important message in reviewing this case law is that courts have historically interpreted "concussion" and postconcussional syndrome cases in extremely different ways, although in ways that appear to reflect progress in the field of brain trauma research and practice. Unfortunately, because the case law is imbued with mutually exclusive definitions of postconcussional syndrome (i.e., a weeklong coma does not equate to an ICD-10-CM postconcussional syndrome diagnosis), along with expert reasoning and opining that is discordant with contemporary scientific knowledge (e.g., it is not exactly "well documented that multiple head injuries ha[ve] a cumulative effect"), exclusive reliance on stare decisis (i.e., legal precedent) is likely to inject low-quality evidence into the factfinding process. Similarly, as was addressed in the two 2018 legal cases from the Supreme Courts of Wyoming and Washington, postconcussional syndrome is very much in use, and experts are successfully opining to a reasonable 
degree of certainty about its long-term negative effects, despite the lack of scientific evidence for this diagnosis.

\section{Admissibility of Postconcussional Syndrome Opinion Evidence}

Three related US Supreme Court decisions (the Daubert Trilogy), as well as some evidentiary rules, effectively function as a sieve to help judges separate out helpful, trustworthy, relevant evidence from ineffectual, misleading, tangential evidence. Table 4 identifies and summarizes the three Supreme Court cases, which go beyond what is articulated in evidentiary rules by expanding the ways in which judges can scrutinize potential expert testimony. Perhaps the most useful of these additional screens is found in the Daubert decision and in the General Electric Company decision. Two of the tests in Daubert are particularly useful. Namely, expert testimony is allowed if (a) the methods relied upon have been scientifically tested and (b) the methods have a known error rate. These somewhat vague concepts come into focus when considered alongside the previous discussion on base rates. Namely, when base rate information on a disorder (e.g., postconcussional syndrome) is cross-tabulated with diagnostic information for a diagnostic method (e.g., an unstructured interview using ICD-10-CM diagnostic criteria or an actual test), an overall error rate can be computed (e.g., Youden's $J$ index or a diagnostic odds ratio). And this error rate can then be explained to a court, for the purposes of deciding whether or not the expert testimony will be helpful to factfinders. The General Electric Company decision builds on Daubert by emphasizing the importance of a cause-effect link between an expert's data and their ultimate opinion. That is, expert testimony can be excluded by judges if the expert's data do not provide a solid foundation for the expert's opinion. So when an expert's data consists of highly subjective clinical evidence that does not rule out alternative causes for the symptoms, or that cannot be reliably measured due to unacceptable error rates, reasonable questions arise as to whether or not the testimony will help factfinders make better decisions. Taken together, these cases emphasize a more quantitative, scientific epistemology when appraising the value of potential expert testimony, thereby making it more challenging for experts to proffer subjective opinions in legal arenas.

Table 5 contains the rules operating at the federal level and in states adopting the Federal Rules of Evidence, which tend to have indirect application in states that have not fully adopted the Federal Rules of Evidence. For example, New Mexico has adopted the Uniform Rules of Evidence, which are very close approximations of the Federal Rules of Evidence. Whereas Rule 702 at the federal level is fleshed out in great detail (see Table 5), the New Mexico equivalent of this rule, NM 11-702, still captures much of the essence of Rule 702:

A witness who is qualified as an expert by knowledge, skill, experience, training, or education may testify in the form of an opinion or otherwise if the expert's scientific, technical, or other specialized knowledge will help the trier of fact to understand the evidence or to determine a fact in issue.

Just as the Daubert Trilogy makes it harder for experts to opine on ultimate legal matters, so do rules of evidence. In

Table 4 Daubert trilogy

\begin{tabular}{ll}
\hline Case & Significance \\
\hline $\begin{array}{l}\text { Daubert v. Merrell Dow Pharmaceuticals, } \\
\text { Inc., 509 U.S. } 579 \text { (1993) }\end{array}$ & $\begin{array}{l}\text { In federal courts and states that have adopted Daubert, four tests are applied by } \\
\text { judges to ascertain the admissibility of expert testimony; namely, experts' } \\
\text { methods must (1) be "scientifically valid," (2) be "published or [have been] } \\
\text { subjected to peer review," (3) have a "known or potential rate of error," and/ } \\
\text { or (4) have some acceptance within the scientific community. }\end{array}$ \\
$\begin{array}{l}\text { Expert testimony can be excluded by judges if the cause-effect link between the } \\
\text { expert's data and the expert's ultimate opinion is lacking: “...nothing in either }\end{array}$ \\
$\begin{array}{l}\text { Daubert or the Federal Rules of Evidence requires a district court to admit } \\
\text { opinion evidence that is connected to existing data only by the ipse dixit of } \\
\text { the expert. A court may conclude that there is simply too great an analytical } \\
\text { gap between the data and the opinion proffered." And short of flagrant abuses } \\
\text { of power, trial judges' decisions concerning the admission of expert testimony } \\
\text { cannot be subsequently overturned: "We hold, therefore, that abuse of discretion } \\
\text { is the proper standard by which to review a district court's decision to admit or } \\
\text { exclude scientific evidence." }\end{array}$
\end{tabular}


Table 5 Federal rules of evidence pertaining to expert testimony

Rule Interpretation

104(a). Questions of admissibility generally

Trial judges can screen out non-experts through a preliminary expert-questioning process, i.e., voir dire, before a jury is presented with any evidence. These are sometimes called Daubert hearings.

401. Definition of "relevant evidence"

“'Relevant evidence' means evidence having any tendency to make the existence of any fact that is of consequence to the determination of the action more probable or less probable than it would be without the evidence."

402. ... Irrelevant evidence inadmissible

"...Evidence which is not relevant is not admissible."

403. Exclusion of relevant evidence on grounds of prejudice, confusion, or waste of time

702. Testimony by experts

“...[even relevant] evidence may be excluded if its probative value is substantially outweighed by the danger of unfair prejudice, confusion of the issues, or misleading the jury, or by considerations of undue delay, waste of time, or needless presentation of cumulative evidence."

"If scientific, technical, or other specialized knowledge will assist the trier of fact to understand the evidence or to determine a fact in issue, a witness qualified as an expert by knowledge, skill, experience, training, or education, may testify thereto in the form of an opinion or otherwise, if (1) the testimony is based upon sufficient facts or data, (2) the testimony is the product of reliable principles and methods, and (3) the witness has applied the principles and methods reliably to the facts of the case."

703. Bases of opinion testimony by experts

Experts are afforded more latitude regarding the foundation their opinions, unless the judge decides otherwise.

Whereas lay/fact/sentient witnesses cannot offer opinions that go beyond "the perception of the witness" (Rule 701), experts can form expert opinions based on information that would otherwise be seen as inadmissible hearsay, as long as the information is "of a type reasonably relied upon by experts in the particular field in forming opinions or inferences upon the subject..." For example, an expert can rely on any of the following: ratings made by a parent on the adaptive/real-world functioning of their child, ratings made by a work supervisor or boss on the functioning of an employee, or information (e.g., psychological test scores) contained in a psychological report produced by another healthcare professional.

704 (a) \& (b). Opinion on ultimate issue

Experts can offer opinions about the ultimate legal question/issue, excluding "the mental state or condition of a defendant in a criminal case [as to] whether the defendant did or did not have the mental state or condition constituting an element of the crime charged or of a defense thereto."

705. Disclosure of facts or data underlying expert opinion
An expert is allowed to proceed directly to offering their opinion "without first testifying to the underlying facts or data, unless the court requires otherwise." However, the expert is still "required to disclose the underlying facts or data on cross-examination" if asked to do so.
FRE 104(a), for example, an attorney, or trial judge presiding over a case where postconcussional syndrome plays a central role, might question prospective experts on the difference between the four categories of traumatic brain injury found in Table 1, especially mTBI versus complicated-mild TBI. Similarly, voir dire questions (i.e., questions posed preliminarily to gauge the expert's fitness) could be directed toward a prospective expert's familiarity with the illusory correlation in relation to the postconcussional syndrome diagnosis. Of equal importance, experts opining about a cause-effect link between concussion and postconcussional syndrome should be able to provide information on the error rate associated with their methods for diagnosing, or not diagnosing, postconcussional syndrome. 


\section{Conclusions}

Today, there are important distinctions between mTBIs, complicated-mild TBIs, moderate TBIs, and severe TBIs that did not exist in previous decades. Attorneys accepting cases involving mTBIs and postconcussional syndrome need to know about these distinctions, as do the factfinders. Equally important, attorneys and factfinders need to know that the postconcussional syndrome diagnosis is impeachable for many reasons: there is no reliable way of measuring organicity, there are unexpectedly powerful psychological effects, intentional symptom production is often not addressed, illusory correlations are not considered, alternative explanations for symptom expression are not ruled out, base rate information is ignored, and iatrogenic effects confound symptom expression. Perhaps some alternative diagnosis is called for, but one that does not assert a causal nexus between a concussion and longterm brain damage.

For those who continue to use a postconcussional syndrome diagnosis to justify ongoing and, therefore, costly services (e.g., rehabilitative therapies), reasonable questions can be posed concerning inadvertent harm (i.e., iatrogenesis) engendered by telling patients they need ongoing mTBI treatment. A better approach, and one endorsed by the WHO Collaborating Task Force on mTBI (Borg et al., 2004) and others (McCrea et al., 2009; Minderhoud et al., 1980; Mittenberg \& Burton, 1994; Ponsford, 2014; Ponsford, 2005; Ponsford et al., 2001, 2002; Wade et al., 1998), is to accurately educate those with mTBIs and encourage a return to normal, low-risk activity after a matter of days (Silverberg \& Iverson, 2013). Unfortunately, for clinicians who challenge the postconcussional syndrome diagnosis, there is an increasing threat of retaliation from patients, their family members, and even from their healthcare providers, given how invested people become in a medical explanation for their difficulties.

Because current research indicates that the base rate for postconcussional syndrome is extremely low (McCrea, 2008), if not 0 (e.g., Boone, 2013; Rohling, LanghinrichsenRohling, \& Axelrod, 2017), legal challenges can justifiably be raised when this questionable diagnosis is made with reasonable medical certainty because methods used to make the diagnosis are not likely to have demonstrated an accuracy rate that can overcome the low base rate. Assuming a 2.5\% base rate for postconcussional syndrome and a postconcussional syndrome test with .68 sensitivity and .69 specificity, the clinician diagnosing postconcussional syndrome is only going to provide the court with a correct diagnosis about $37 \%$ of the time, which does not even outperform chance nor does it outperform the $97.5 \%$ accuracy rate associated with playing the base rate and not diagnosing postconcussional syndrome. As explained by Faust and Ahern (2012), if a "test achieves a predictive accuracy [rate] of $60 \%$ and playing the base rate [has an] accuracy [rate] of $80 \%$, one uses the base rate over the test...a [method] cannot outperform the base rate unless it achieves an accuracy level that is greater than the frequency of the more common occurrence (or nonoccurrence)" (p. 196). Legal challenges made to experts in postconcussional syndrome cases can be asserted in the early stages of a case, during voir dire (i.e., the formal, preliminary questioning of an expert to appraise their fitness), on the basis that the methodology for diagnosing postconcussional syndrome cannot surmount the hurdles established by the Daubert Trilogy (e.g., having a known error rate that justifies the methods) and related evidentiary rules (e.g., "the testimony is the product of reliable principles and methods"). Understandably, some courts appear to lack adequate awareness about these nuanced issues.

Twenty years ago, Bauer's presentation, "Brain Damage Caused by Collision with Forensic Neuropsychologists," helped neuropsychologists develop a more accurate understanding of mTBIs and their long-term effects. Ideally, the present article will have a similar impact on attorneys and factfinders today, thereby providing clarification about mTBIs and increasing the likelihood of just legal outcomes.

Acknowledgments We want to thank Eric Y. Drogin, Arnold Purisch, Jill Portnoy, and Joe Barda for providing valuable commentary on earlier versions of this manuscript.

\section{Compliance with Ethical Standards}

Conflict of Interest The authors declare that they have no conflict of interest.

\section{References}

American Psychiatric Association. (2000). Diagnostic and statistical manual of mental disorders (revised 4th ed.). Washington, DC: Author.

Anderson-Barnes, V. C., Weeks, S. R., \& Tsao, J. W. (2010). Mild traumatic brain injury update. CONTINUUM: Lifelong Learning in Neurology, 16, 17-26.

Armistead-Jehle, P. (2010). Symptom validity test performance in US veterans referred for evaluation of mild TBI. Applied Neuropsychology, 17(1), 52-59.

Barker, M. J., Greenwood, K. M., Jackson, M., \& Crowe, S. F. (2004). Cognitive effects of long-term benzodiazepine use. CNS Drugs, 18 , $37-48$.

Basso, M., Miller, A., Estevis, E., \& Combs, D. (2013). Neuropsychological deficits in major depressive disorder: Correlates and conundrums. In P. Arnett (Ed.), Secondary influences on neuropsychological test performance (pp. 39-66). New York: Oxford University Press.

Basso, M. R., \& Bornstein, R. A. (1999). Relative memory deficits in recurrent versus first-episode major depression on a word-list learning task. Neuropsychology, 13, 557-563.

Bauer, R. M. (1997). Brain damage caused by collision with forensic neuropsychologists. Paper presented at the International Neuropsychology Society, Orlando, FL, February 7. 
Belanger, H. G., Spiegel, E., \& Vanderploeg, R. D. (2010). Neuropsychological performance following a history of multiple self-reported concussions: A meta-analysis. Journal of the International Neuropsychological Society, 16, 262-267.

Benbadis, S. R. (2005). Psychogenic non-epileptic seizures. The Treatment of Epilepsy: Principles and Practice, 4, 623-630.

Benbadis, S. R., Blustein, J. N., \& Sunstad, L. (2000). Should patients with psychogenic nonepileptic seizures be allowed to drive? Epilepsia, 41, 895-897.

Bergman, D. A., Baltz, R. D., Cooley, J. R., Coombs, J. B., Goldberg, M. J., Homer, C. J., ... Shea, D. W. (1999). The management of minor closed head injury in children. Pediatrics, 104, 1407-1415.

Bigler, E. D., \& Maxwell, W. D. (2012). Neuropathology of mild traumatic brain injury: Relationship to neuroimaging findings. Brain Imaging and Behavior, 6, 108-136.

Bijur, P. E., Haslum, M., \& Golding, J. (1996). Cognitive outcomes of multiple mild head injuries in children. Journal of Developmental \& Behavioral Pediatrics, 17, 143-148.

Binder, L. M. (1997). A review of mild head trauma. Part II: Clinical implications. Journal of Clinical and Experimental Neuropsychology, 19, 432-457.

Boone, K. B. (2013). Clinical practice of forensic neuropsychology: An evidence-based approach. New York: Guilford Press.

Borg, J., Holm, L., Peloso, P., Cassidy, J. D., Carroll, L., Von Holst, H., ... Yates, D. (2004). Non-surgical intervention and cost for mild traumatic brain injury: Results of the WHO Collaborating Centre Task Force on Mild Traumatic Brain Injury. Journal of Rehabilitation Medicine, 36, 76-83.

Borum, R., Otto, R., \& Golding, S. (1993). Improving clinical judgment and decision making in forensic evaluation. The Journal of Psychiatry \& Law, 21, 35-76.

Bowles v. Los Lunas Schools, 781 P. 2d 1178 - NM: Court of Appeals 1989.

Bryan, A. G. (2009). Black's law dictionary (Vol. 9, p. 1428). St. Paul: West Publishing Company.

Bush, S. S., \& Myers, T. E. (2013). Neuropsychological services following motor vehicle collisions. Psychological Injury and Law, 6, 3-20.

Carone, D. A., \& Bush, S. S. (2014). Dementia pugilistica and chronic traumatic encephalopathy. In R. Dean \& C. Noggle (Eds.), Cortical dementias (pp. 303-326). New York: Springer.

Carroll, L., Cassidy, J., Holm, L., Kraus, J., \& Coronado, V. (2004). WHO Collaborating Centre Task Force on Mild Traumatic Brain, Injury. Methodological issues and research recommendations for mild traumatic brain injury: The WHO Collaborating Centre Task Force on Mild Traumatic Brain Injury. Journal of Rehabilitation Medicine, 43, 113-125.

Carroll, L. J., Cassidy, J. D., Cancelliere, C., Côté, P., Hincapié, C. A., Kristman, V. L., ... Hartvigsen, J. (2014). Systematic review of the prognosis after mild traumatic brain injury in adults: Cognitive, psychiatric, and mortality outcomes: Results of the International Collaboration on Mild Traumatic Brain Injury Prognosis. Archives of Physical Medicine and Rehabilitation, 95(3), S152-S173.

Cassidy, J. D., Boyle, E., \& Carroll, L. J. (2014). Population-based, inception cohort study of the incidence, course, and prognosis of mild traumatic brain injury after motor vehicle collisions. Archives of Physical Medicine and Rehabilitation, 95(3), S278-S285.

Chapman, L. J., \& Chapman, J. P. (1969). Illusory correlation as an obstacle to the use of valid psychodiagnostic signs. Journal of Abnormal Psychology, 74, 271-280.

Chen, D. K., \& LaFrance, W. C., Jr. (2016). Diagnosis and treatment of nonepileptic seizures. CONTINUUM: Lifelong Learning in Neurology, 22, 116-131.

Cohen, J. (1988). Statistical Power Analysis for the Behavioral Sciences. New York: Routledge.
Collie, A., McCrory, P., \& Makdissi, M. (2006). Does history of concussion affect current cognitive status? British Journal of Sports Medicine, 40, 550-551.

Croskerry, P. (2002). Achieving quality in clinical decision making: Cognitive strategies and detection of bias. Academic Emergency Medicine, 9, 1184-1204.

Curran, H. V. (1991). Benzodiazepines, memory and mood: A review. Psychopharmacology, 105, 1-8.

Daubert v. Merrell Dow Pharmaceuticals, Inc (1993). US (Vol. 509, pp. 579): Supreme Court.

de Gage, S. B., Bégaud, B., Bazin, F., Verdoux, H., Dartigues, J.-F., Pérès, K., ... Pariente, A. (2012). Benzodiazepine use and risk of dementia: Prospective population based study. BMJ, 345, e6231.

Decobert, F., Grabar, S., Merzoug, V., Kalifa, G., Ponsot, G., Adamsbaum, C., ... Des Portes, V. (2005). Unexplained mental retardation: Is brain MRI useful? Pediatric Radiology, 35, 587-596.

Denning, J. H., \& Shura, R. D. (2017). Cost of malingering mild traumatic brain injury-related cognitive deficits during compensation and pension evaluations in the veterans benefits administration. Applied Neuropsychology: Adult, 1-16.

Dikmen, S., Machamer, J., \& Temkin, N. (2017). Mild traumatic brain injury: Longitudinal study of cognition, functional status, and posttraumatic symptoms. Journal of Neurotrauma, 34, 1524-1530.

Durham v. Gulf Interstate Engineering Company (1964). P. $2 d$ (Vol. 393 , pp. 15): NM: Supreme Court.

Evans, R. W. (2017). Incidental findings and normal anatomical variants on MRI of the brain in adults for primary headaches. Headache: The Journal of Head and Face Pain, 57, 780-791.

Faust, D., \& Ahern, D. C. (2012). Clinical judgment and prediction. In D. Faust (Ed.), Coping with psychiatric and psychological testimony (6th ed., pp. 147-208). New York: Oxford University Press.

Fay, T. B., Yeates, K. O., Taylor, H. G., Bangert, B., Dietrich, A., Nuss, K. E., et al. (2010). Cognitive reserve as a moderator of postconcussive symptoms in children with complicated and uncomplicated mild traumatic brain injury. Journal of the International Neuropsychological Society, 16, 94-105.

Flynn, F. G. (2010). Memory impairment after mild traumatic brain injury. CONTINUUM: Lifelong Learning in Neurology, 16, 79-109.

Foa, E. B., Cashman, L., Jaycox, L., \& Perry, K. (1997). The validation of a self-report measure of posttraumatic stress disorder: The Posttraumatic Diagnostic Scale. Psychological Assessment, 9 , 445-451.

Fox, D. D. (2017). Persistent postconcussion syndrome. In K. B. Boone (Ed.), Neuropsychological evaluation of somatoform and other functional somatic conditions (pp. 220-243). New York: Routledge.

Fox, D. D., Lees-Haley, P. R., Earnest, K., \& Dolezal-Wood, S. (1995). Base rates of postconcussive symptoms in health maintenance organization patients and controls. Neuropsychology, 9, 606-611.

Frederick, R. I. (2000). Mixed group validation: A method to address the limitations of criterion group validation in research on malingering detection. Behavioral Sciences \& the Law, 18(6), 693-718.

General Electric Co. v. Joiner (1997). US (Vol. 522, pp. 136): Supreme Court.

Genovese, C. R., Lazar, N. A., \& Nichols, T. (2002). Thresholding of statistical maps in functional neuroimaging using the false discovery rate. Neuroimage, $15,870-878$.

Gerbeding, J., \& Binder, S. (2003). Report to congress on mild traumatic brain injury in the United States: Steps to preventing a serious public health problem. Atlanta: Centers for Disease Control and Prevention.

Gill, J., French, L., Lange, R., Lippa, S., \& Brickell, T. (2018). Relationship between plasma tau and amyloid-beta-42 with neurocognition following mild traumatic brain injury. Archives of Physical Medicine and Rehabilitation, 99, e175.

Gillig, P. M. (2013). Psychogenic nonepileptic seizures. Innovations in Clinical Neuroscience, 10, 15-18. 
Giza, C. C., Kutcher, J. S., Ashwal, S., Barth, J., Getchius, T. S., Gioia, G. A., et al. (2013). Summary of evidence-based guideline update: Evaluation and managment of concussion in sports: Report of the Gudeline Development Subcommittee of American Academy of Neurology. Neurology, 80, 2250-2257. https://doi.org/10.1212/ WNL.0b013e31828d57dd.

Godbolt, A. K., Cancelliere, C., Hincapié, C. A., Marras, C., Boyle, E., Kristman, V. L., ... Cassidy, J. D. (2014). Systematic review of the risk of dementia and chronic cognitive impairment after mild traumatic brain injury: Results of the International Collaboration on Mild Traumatic Brain Injury Prognosis. Archives of Physical Medicine and Rehabilitation, 95(3), S245-S256.

Goodheart, C. D. (2014). A primer for ICD-10-CM users: Psychological and behavioral conditions. Washington, DC: American Psychological Association.

Gouvier, W. D., Cubic, B., Jones, G., Brantley, P., \& Cutlip, Q. (1992). Postconcussion symptoms and daily stress in normal and headinjured college populations. Archives of Clinical Neuropsychology, 7, 193-211

Gouvier, W. D., Uddo-Crane, M., \& Brown, L. M. (1988). Base rates of post-concussional symptoms. Archives of Clinical Neuropsychology, 3, 273-278.

Grover, H., Qian, Y., Boada, F. E., Lakshmanan, K., Flanagan, S., \& Lui, Y. W. (2018). MRI evidence of altered callosal sodium in mild traumatic brain injury. American Journal of Neuroradiology, 39, 2200-2204.

Gunstad, J., \& Suhr, J. A. (2004). Cognitive factors in postconcussion syndrome symptom report. Archives of Clinical Neuropsychology, 19, 391-405.

Guskiewicz, K. M., Marshall, S. W., Broglio, S. P., Cantu, R. C., \& Kirkendall, D. T. (2002). No evidence of impaired neurocognitive performance in collegiate soccer players. American Journal of Sports Medicine, 30, 157-162.

Hall, W., \& Degenhardt, L. (2009). Adverse health effects of non-medical cannabis use. The Lancet, 374, 1383-1391.

Hibbard, M. R., Bogdany, J., Uysal, S., Kepler, K., Silver, J. M., Gordon, W. A., ... Haddad, L. (2000). Axis II psychopathology in individuals with traumatic brain injury. Brain Injury, 14, 45-61.

Hofman, P. A., Stapert, S. Z., van Kroonenburgh, M. J., Jolles, J., de Kruijk, J., \& Wilmink, J. T. (2001). MR imaging, single-photon emission CT, and neurocognitive performance after mild traumatic brain injury. American Journal of Neuroradiology, 22, 441-449.

Holm, L., David Cassidy, J., Carroll, L., \& Borg, J. (2005). Summary of the WHO collaborating Centre for neurotrauma task force on mild traumatic brain injury. Journal of Rehabilitation Medicine, 37, 137141.

Hughes, D. G., Jackson, A., Mason, D. L., Berry, E., Hollis, S., \& Yates, D. W. (2004). Abnormalities on magnetic resonance imaging seen acutely following mild traumatic brain injury: Correlation with neuropsychological tests and delayed recovery. Neuroradiology, 46, $550-558$.

Hung, R., Carroll, L. J., Cancelliere, C., Côté, P., Rumney, P., Keightley, M., ... Cassidy, J. D. (2014). Systematic review of the clinical course, natural history, and prognosis for pediatric mild traumatic brain injury: Results of the International Collaboration on Mild Traumatic Brain Injury Prognosis. Archives of Physical Medicine and Rehabilitation, 95(3), S174-S191.

Institute of Medicine. (2006). Evaluating the HRSA traumatic brain injury program. Washington, DC: National Academic Press.

Iverson, G. L. (2006). Misdiagnosis of the persistent postconcussion syndrome in patients with depression. Archives of Clinical Neuropsychology, 21, 303-310.

Iverson, G. L., Brooks, B. L., Ashton, V. L., \& Lange, R. T. (2010). Interview versus questionnaire symptom reporting in people with the postconcussion syndrome. The Journal of Head Trauma Rehabilitation, 25, 23-30.
Iverson, G. L., Brooks, B. L., Lovell, M. R., \& Collins, M. W. (2006). No cumulative effects for one or two previous concussions. British Journal Sports Medicine, 40(1), 72-75. https://doi.org/10.1136/ bjsm.2005.020651.

Iverson, G. L., \& Lange, R. T. (2003). Examination of "postconcussionlike" symptoms in a healthy sample. Applied Neuropsychology, 10, 137-144.

Iverson, G. L., \& McCracken, L. M. (1997). "Postconcussive" symptoms in persons with chronic pain. Brain Injury, 11, 783-790.

Jacobs, B., Beems, T., Stulemeijer, M., van Vugt, A. B., van der Vliet, T. M., Borm, G. F., \& Vos, P. E. (2010). Outcome prediction in mild traumatic brain injury: Age and clinical variables are stronger predictors than CT abnormalities. Journal of Neurotrauma, 27(4), 655 668.

Kashluba, S., Hanks, R. A., Casey, J. E., \& Millis, S. R. (2008). Neuropsychologic and functional outcome after complicated mild traumatic brain injury. Archives of Physical Medicine and Rehabilitation, 89, 904-911.

Katzman, G. L., Dagher, A. P., \& Patronas, N. J. (1999). Incidental findings on brain magnetic resonance imaging from 1000 asymptomatic volunteers. Journal of the American Medical Association, 282, 36-39.

Kay, T., Harrington, D. E., Adams, R., Anderson, T., Berrol, S., Cicerone, K, ... Malec, J. (1993). American Congress of Rehabilitation Medicine, Head Injury Interdisciplinary Special Interest Group.(1993). Definition of mild traumatic brain injury. Journal of Head Trauma Rehabilitation, 8, 86-87.

Kim, B. S., Illes, J., Kaplan, R. T., Reiss, A., \& Atlas, S. W. (2002). Incidental findings on pediatric MR images of the brain. American Journal of Neuroradiology, 23, 1674-1677.

Kristman, V. L., Borg, J., Godbolt, A. K., Salmi, L. R., Cancelliere, C., Carroll, L. J., ... Abara, U. (2014). Methodological issues and research recommendations for prognosis after mild traumatic brain injury: Results of the International Collaboration on Mild Traumatic Brain Injury Prognosis. Archives of Physical Medicine and Rehabilitation, 95(3), S265-S277.

Kulbe, J. R., \& Geddes, J. W. (2016). Current status of fluid biomarkers in mild traumatic brain injury. Experimental Neurology, 275, 334-352.

Kumho Tire Co. v. Carmichael (1999). US (Vol. 526, pp. 137): Supreme Court.

Kurča, E., Sivák, Š., \& Kučera, P. (2006). Impaired cognitive functions in mild traumatic brain injury patients with normal and pathologic magnetic resonance imaging. Neuroradiology, 48, 661-669.

Lagarde, E., Salmi, L.-R., Holm, L. W., Contrand, B., Masson, F., Ribéreau-Gayon, R., ... Cassidy, J. D. (2014). Association of symptoms following mild traumatic brain injury with posttraumatic stress disorder vs postconcussion syndrome. Journal of the American Medical Assocation Psychiatry, 71(9), 1032-1040.

Lande, R. G., \& Williams, L. B. (2013). Prevalence and characteristics of military malingering. Military Medicine, 178(1), 50-54.

Lange, R. T., Iverson, G. L., Brubacher, J. R., Mädler, B., \& Heran, M. K. (2012). Diffusion tensor imaging findings are not strongly associated with postconcussional disorder 2 months following mild traumatic brain injury. The Journal of Head Trauma Rehabilitation, 27, $188-198$.

Larrabee, G. (2005). Mild traumatic brain injury. In G. Larrabee (Ed.), Forensic neuropsychology: A scientific approach (pp. 209-236). New York: Oxford University Press.

Larrabee, G. J. (1999). In N. R. Varney \& R. J. Roberts (Eds.), The evaluation and treatment of mild traumatic brain injury Current controversies in mild head injury: Scientific and methodologic considerations (pp. 327-345). Mahwah: Lawrence Erlbaum Associates Publishers.

Larrabee, G. J. (2003). Detection of malingering using atypical performance patterns on standard neuropsychological tests. The Clinical Neuropsychologist, 17(3), 410-425. 
Larrabee, G. J. (2012). Performance validity and symptom validity in neuropsychological assessment. Journal of the International Neuropsychological Society, 18, 625-630.

Leach, J. (2018). 'Give-up-itis' revisited: Neuropathology of extremis. Medical Hypotheses, 120, 14-21.

Lees-Haley, P. R., \& Brown, R. S. (1993). Neuropsychological complaint base rates of 170 personal injury claimants. Archives of Clinical Neuropsychology, 8, 203-209.

Levin, H. S., \& Diaz-Arrastia, R. R. (2015). Diagnosis, prognosis, and clinical management of mild traumatic brain injury. The Lancet Neurology, 14(5), 506-517.

Levin, H. S., Hanten, G., Roberson, G., Li, X., Ewing-Cobbs, L., Dennis, M., ... Schachar, R. (2008). Prediction of cognitive sequelae based on abnormal computed tomography findings in children following mild traumatic brain injury. Journal of Neurosurgery: Pediatrics, 1 , 461-470.

Lewine, J. D., Davis, J. T., Bigler, E. D., Thoma, R., Hill, D., Funke, M., et al. (2007). Objective documentation of traumatic brain injury subsequent to mild head trauma: Multimodal brain imaging with MEG, SPECT, and MRI. The Journal of Head Trauma Rehabilitation, 22, 141-155.

Lezak, M. D., Howieson, D. B., \& Loring, D. W. (2004). Neuropsychological assessment (4th ed.). New York: Oxford Univeristy Press.

Lieberman, M. D., \& Cunningham, W. A. (2009). Type I and type II error concerns in fMRI research: Re-balancing the scale. Social, Cognitive and Affective Neuroscience, 4, 423-428.

Ling, G. S., Marshall, S. A., \& Moore, D. F. (2010). Diagnosis and management of traumatic brain injury. CONTINUUM: Lifelong Learning in Neurology, 16, 27-40.

Loring, D. W., \& Meador, K. J. (1999). INS dictionary of neuropsychology. Oxford University Press.

Matter of Williams (2018). P. 3d (Vol. 409, pp. 1219). Wyoming: Supreme Court.

McCrea, M. (2008). Mild traumatic brain injury and postconcussion syndrome: The new evidence base for diagnosis and treatment. New York: Oxford University Press.

McCrea, M., Iverson, G. L., McAllister, T. W., Hammeke, T. A., Powell, M. R., Barr, W. B., et al. (2009). An integrated review of recovery after mild traumatic brain injury (MTBI): Implications for clinical management. The Clinical Neuropsychologist, 23, 1368-1390.

Meares, S., Shores, E. A., Taylor, A. J., Batchelor, J., Bryant, R. A., Baguley, I. J ... Marosszeky, J.E. (2011). The prospective course of postconcussion syndrome: The role of mild traumatic brain injury. Neuropsychology, 25, 454-465.

Melton, G. B., Petrila, J., Poythress, N. G., Slobogin, C., Otto, R. K., Mossman, D., ... Condie, L.O. (2017). Psychological evaluations for the courts: A handbook for mental health professionals and lawyers. New York: Guilford.

Mickevičiene, D., Schrader, H., Obelieniene, D., Surkiene, D., Kunickas, R., Stovner, L., \& Sand, T. (2004). A controlled prospective inception cohort study on the post-concussion syndrome outside the medicolegal context. European Journal of Neurology, 11, 411-419.

Miller, R. D. (2006). Reasonable medical certainty: A rose by any other name. The Journal of Psychiatry \& Law, 34, 273-290.

Minderhoud, J., Boelens, M., Huizenga, J., \& Saan, R. (1980). Treatment of minor head injuries. Clinical Neurology and Neurosurgery, 82, 127-IN127.

Mittenberg, W., \& Burton, D. B. (1994). A survey of treatments for postconcussion syndrome. Brain Injury, 8, 429-437.

Mittenberg, W., DiGiulio, D. V., Perrin, S., \& Bass, A. E. (1992). Symptoms following mild head injury: Expectation as aetiology. Journal of Neurology, Neurosurgery \& Psychiatry, 55, 200-204.

Mittenberg, W., Patton, C., Canyock, E. M., \& Condit, D. C. (2002). Base rates of malingering and symptom exaggeration. Journal of Clinical and Experimental Neuropsychology, 24(8), 1094-1102.
Morris, Z., Whiteley, W. N., Longstreth, W., Weber, F., Lee, Y.-C., Tsushima, Y., ... Wardlaw, J.M. (2009). Incidental findings on brain magnetic resonance imaging: Systematic review and meta-analysis. $B M J, 339, \mathrm{~b} 3016$.

Nair, D. R. (2016). Management of drug-resistant epilepsy. CONTINUUM: Lifelong Learning in Neurology, 22, 157-172.

Nisbett, R. E., Zukier, H., \& Lemley, R. E. (1981). The dilution effect: Nondiagnostic information weakens the implications of diagnostic information. Cognitive Psychology, 13(2), 248-277.

Ortinski, P., \& Meador, K. J. (2004). Cognitive side effects of antiepileptic drugs. Epilepsy \& Behavior, 5, 60-65.

Panenka, W. J., Lange, R. T., Bouix, S., Shewchuk, J. R., Heran, M. K., Brubacher, J. R., ... Iverson, G. L. (2015). Neuropsychological outcome and diffusion tensor imaging in complicated versus uncomplicated mild traumatic brain injury. PLoS One, 10(4), e 0122746.

Papa, L., Ramia, M. M., Kelly, J. M., Burks, S. S., Pawlowicz, A., \& Berger, R. P. (2013). Systematic review of clinical research on biomarkers for pediatric traumatic brain injury. Journal of Neurotrauma, 30(5), 324-338.

Pariente, A., de Gage, S. B., Moore, N., \& Bégaud, B. (2016). The benzodiazepine-dementia disorders link: Current state of knowledge. CNS Drugs, 30, 1-7.

Pellman, E. J., Lovell, M. R., Viano, D. C., Casson, I. R., \& Tucker, A. M. (2004). Concussion in professional football: Neuropsychological testing-Part 6. Neurosurgery, 55, 1290-1305.

Ponsford, J. (2005). Rehabilitation interventions after mild head injury. Current Opinion in Neurology, 18, 692-697.

Ponsford, J. (2014). Short and long-term outcomes in survivors of traumatic brain injury. Understanding traumatic brain injury: Current research and future directions. pp 190-214.

Ponsford, J., Cameron, P., Fitzgerald, M., Grant, M., \& Mikocka-Walus, A. (2011). Long-term outcomes after uncomplicated mild traumatic brain injury: A comparison with trauma controls. Journal of Neurotrauma, 28(6), 937-946.

Ponsford, J., Willmott, C., Rothwell, A., Cameron, P., Ayton, G., Nelms, R., ... Ng, K. (2001). Impact of early intervention on outcome after mild traumatic brain injury in children. Pediatrics, 108, 12971303.

Ponsford, J., Willmott, C., Rothwell, A., Cameron, P., Kelly, A., Nelms, R., ... Curran, C. (2002). Impact of early intervention on outcome following mild head injury in adults. Journal of Neurology, Neurosurgery \& Psychiatry, 73, 330-332.

Pritchard, J. M., \& Hopp, J. L. (2014). Psychogenic nonepileptic seizures. Journal of Clinical Outcomes Management, 21, 271-279.

Research Advisory Committee on Gulf War Veterans' Illness. (2008). Gulf War illness and the health of Gulf War veterans: Scientific findings and recommendations. Washington, DC: U.S. Government Printing Office.

Reuber, M., Pukrop, R., Bauer, J., Helmstaedter, C., Tessendorf, N., \& Elger, C. E. (2003). Outcome in psychogenic nonepileptic seizures: 1 to 10-year follow-up in 164 patients. Annals of Neurology, 53, 305-311.

Riechers, R. G., \& Ruff, R. L. (2010). Rehabilitation in the patient with mild traumatic brain injury. CONTINUUM: Lifelong Learning in Neurology, 16, 128-149.

Rogers, R. (2008). An introduction to response styles. In R. Rogers (Ed.), Clinical assessment of malingering and deception (3rd ed., pp. $3-$ 13). New York: Guilford.

Rogers, R., \& Bender, S. (2013). Evaluation of malingering and related response styles. In A. M. Goldstein (Ed.), Handbook of psychology, 11 (Forensic Psychology) (pp. 517-540). Hoboken: John Wiley \& Sons, Inc.

Rogers, R., Harrell, E. H., \& Liff, C. D. (1993). Feigning neuropsychological impairment: A critical review of methodological and clinical considerations. Clinical Psychology Review, 13(3), 255-274. 
Rogers, R., Sewell, K. W., \& Goldstein, A. M. (1994). Explanatory models of malingering: A prototypical analysis. Law and Human Behavior, 18(5), 543-552.

Rogers, R., \& Shuman, D. (2006). Fundamentals of forensic practice: Mental health and criminal law. New York: Springer Science \& Business Media.

Rohling, M., Axelrod, B., \& Langhinrichsen-Rohling, J. (2017). Fundamental forensic statistics: Statistics every forensic neuropsychologist must know. In S. S. Bush, G. J. Demakis, \& M. 1. Rohling (Eds.), APA handbook of forensic neuropsychology (pp. 3-22). Washington, DC: American Psychological Association.

Rohling, M., Langhinrichsen-Rohling, J., \& Axelrod, B. (2017). Mild traumatic brain injury. In S. S. Bush, G. J. Demakis, \& M. L. Rohling (Eds.), APA handbook of forensic neuropsychology (pp. 147-200). Washington, DC: American Psychological Association.

Ruff, R. M., Camenzuli, L., \& Mueller, J. (1996). Miserable minority: Emotional risk factors that influence the outcome of a mild traumatic brain injury. Brain Injury, 10, 551-566.

Ruff, R. M., Iverson, G. L., Barth, J. T., Bush, S. S., \& Broshek, D. K. (2009). Recommendations for diagnosing a mild traumatic brain injury: A National Academy of Neuropsychology education paper. Archives of Clinical Neuropsychology, 24, 3-10.

Ruff, R. M., Klopfer, J., \& Blank, J. (2016). Homogenous base rates for malingering in neuropsychological examination of litigants. Psychological Injury and Law, 9(2), 143-153.

Ruxton, K., Woodman, R. J., \& Mangoni, A. A. (2015). Drugs with anticholinergic effects and cognitive impairment, falls and allcause mortality in older adults: A systematic review and meta-analysis. British Journal of Clinical Pharmacology, 80, 209-220.

Salmi, L. R., Cassidy, J. D., Holm, L., Cancelliere, C., Côté, P., \& Borg, J. (2014). Introduction to the findings of the international collaboration on mild traumatic brain injury prognosis: What is a prognostic study? Archives of Physical Medicine and Rehabilitation, 95(3), S95-S100.

Sanchez v. Molycorp, Inc (1985). P. $2 d$ (Vol. 703, pp. 925). NM: Court of Appeals.

Sharland, M. J., \& Gfeller, J. D. (2007). A survey of neuropsychologists' beliefs and practices with respect to the assessment of effort. Archives of Clinical Neuropsychology, 22(2), 213-223.

Shin, S. S., Bales, J. W., Dixon, C. E., \& Hwang, M. (2017). Structural imaging of mild traumatic brain injury may not be enough: Overview of functional and metabolic imaging of mild traumatic brain injury. Brain Imaging and Behavior, 11(2), 591-610.

Silverberg, N. D., \& Iverson, G. L. (2013). Is rest after concussion "the best medicine?": recommendations for activity resumption following concussion in athletes, civilians, and military service members. The Journal of Head Trauma Rehabilitation, 28(4), 250-259.

Silverberg, N. D., Gardner, A. J., Brubacher, J. R., Panenka, W. J., Li, J. J., \& Iverson, G. L. (2015). Systematic review of multivariable prognostic models for mild traumatic brain injury. Journal of Neurotrauma, 32(8), 517-526.

Slick, D. J., Tan, J. E., Strauss, E. H., \& Hultsch, D. F. (2004). Detecting malingering: A survey of experts' practices. Archives of Clinical Neuropsychology, 19(4), 465-473.

Sosin, D. M., Sniezek, J. E., \& Thurman, D. J. (1996). Incidence of mild and moderate brain injury in the United States, 1991. Brain Injury, $10,47-54$

State v. Schierman, 415 P. 3d 106 - Wash: Supreme Court 2018.

Stein, S. C. (1996). Classification of head injury. In R. K. Narayan, J. T. Povlishock, \& J. E. Wilberger Jr. (Eds.), Neurotrauma (pp. 31-42). New York: McGraw-Hill.

Stranks, E. K., \& Crowe, S. F. (2016). The cognitive effects of obstructive sleep apnea: An updated meta-analysis. Archives of Clinical Neuropsychology, 31, 186-193.
Suhr, J., \& Wei, C. (2013). Response expectancies and their potential influence in neuropsychological evaluation. In P. Arnett (Ed.), Secondary influences on neuropsychological test performance (pp. 182-200). New York: Oxford University Press.

Suhr, J. A., \& Gunstad, J. (2002). "Diagnosis threat": The effect of negative expectations on cognitive performance in head injury. Journal of Clinical and Experimental Neuropsychology, 24, 448-457.

Sullivan, M. J., Hall, E., Bartolacci, R., Sullivan, M. E., \& Adams, H. (2002). Perceived cognitive deficits, emotional distress and disability following whiplash injury. Pain Research and Management, 7, $120-126$.

Thompson v. Anderman (1955). P. $2 d$ (Vol. 285, pp. 507). NM: Supreme Court.

Tyson, B. T., Baker, S., Greenacre, M., Kent, K. J., Lichtenstein, J. D., Sabelli, A., \& Erdodi, L. A. (2018). Differentiating epilepsy from psychogenic nonepileptic seizures using neuropsychological test data. Epilepsy \& Behavior, 87, 39-45.

Uzzell, B. (1999). Mild head injury: Much ado about something. In N. R. Varney \& R. J. Roberts (Eds.), The evaluation and treatment of mild traumatic brain injury (pp. 13-26). Mahwah: Lawrence Erlbaum Associates.

van der Naalt, J., Timmerman, M. E., de Koning, M. E., van der Horn, H. J., Scheenen, M. E., Jacobs, B., ... Spikman, J. M. (2017). Early predictors of outcome after mild traumatic brain injury (UPFRONT): An observational cohort study. The Lancet Neurology, 16(7), 532-540.

Vernooij, M. W., Ikram, M. A., Tanghe, H. L., Vincent, A. J., Hofman, A., Krestin, G. P, ... van der Lugt, A. (2007). Incidental findings on brain MRI in the general population. New England Journal of Medicine, 357, 1821-1828.

Voon, V., Brezing, C., Gallea, C., Ameli, R., Roelofs, K., LaFrance, W. C., Jr., \& Hallett, M. (2010). Emotional stimuli and motor conversion disorder. Brain, 133(5), 1526-1536.

Vore, D. (2007). The disability psychological independent medical evaluation: Case law, ethical issues, and procedures. In A. M. Goldstein (Ed.), Forensic psychology: Emerging topics and expanding roles (pp. 489-510). Hoboken: John Wiley \& Sons, Inc.

Wade, D., King, N., Wenden, F., Crawford, S., \& Caldwell, F. (1998). Routine follow up after head injury: A second randomised controlled trial. Journal of Neurology, Neurosurgery \& Psychiatry, 65, $177-183$

Wäljas, M., Iverson, G. L., Lange, R. T., Hakulinen, U., Dastidar, P., Huhtala, H., ... Öhman, J. (2015). A prospective biopsychosocial study of the persistent post-concussion symptoms following mild traumatic brain injury. Journal of Neurotrauma, 32(8), 534-547.

Wall, A. M., Graver, C. J., \& Shurak, N. R. (2013). Base rates of suboptimal effort in a broad clinical population. The Clinical Neuropsychologist, 27(4), 607-608.

Weissman, H. N. (1990). Distortions and deceptions in self presentation: Effects of protracted litigation in personal injury cases. Behavioral Sciences \& the Law, 8, 67-74.

White v. Guest Services, Inc. (2018) No. COA17-1156 (N.C. Ct. App. June 5, 2018).

Williams, D. H., Levin, H. S., \& Eisenberg, H. M. (1990). Mild head injury classification. Neurosurgery, 27, 422-428.

Wong, J. L., Regennitter, R. P., \& Barrios, F. (1994). Base rate and simulated symptoms of mild head injury among normals. Archives of Clinical Neuropsychology, 9, 411-425.

World Health Organization. (2018). International classificaiton of diseases, $10^{\text {th }}$ revision, clinical modification (ICD-10-CM). http:// www.icd10data.com/. Accessed 11 Jan 2018

Young, G. (2015). Malingering in forensic disability-related assessments: Prevalence 15 $\pm 15 \%$. Psychological Injury and Law, 8(3), 188-199. 
Youngjohn, J. R., Burrows, L., \& Erdal, K. (1995). Brain damage or compensation neurosis? The controversial post-concussion syndrome. The Clinical Neuropsychologist, 9(2), 112-123.

Yuh, E. L., Cooper, S. R., Mukherjee, P., Yue, J. K., Lingsma, H. F., Gordon, W. A., ... Vassar, M. J. (2014). Diffusion tensor imaging for outcome prediction in mild traumatic brain injury: A TRACKTBI study. Journal of Neurotrauma, 31(17), 1457-1477.
Zetterberg, H., Smith, D. H., \& Blennow, K. (2013). Biomarkers of mild traumatic brain injury in cerebrospinal fluid and blood. Nature Reviews Neurology, 9(4), 201-210.

Publisher's Note Springer Nature remains neutral with regard to jurisdictional claims in published maps and institutional affiliations. 